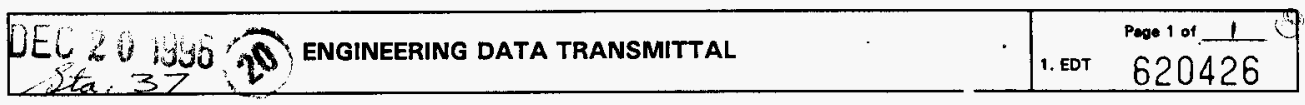

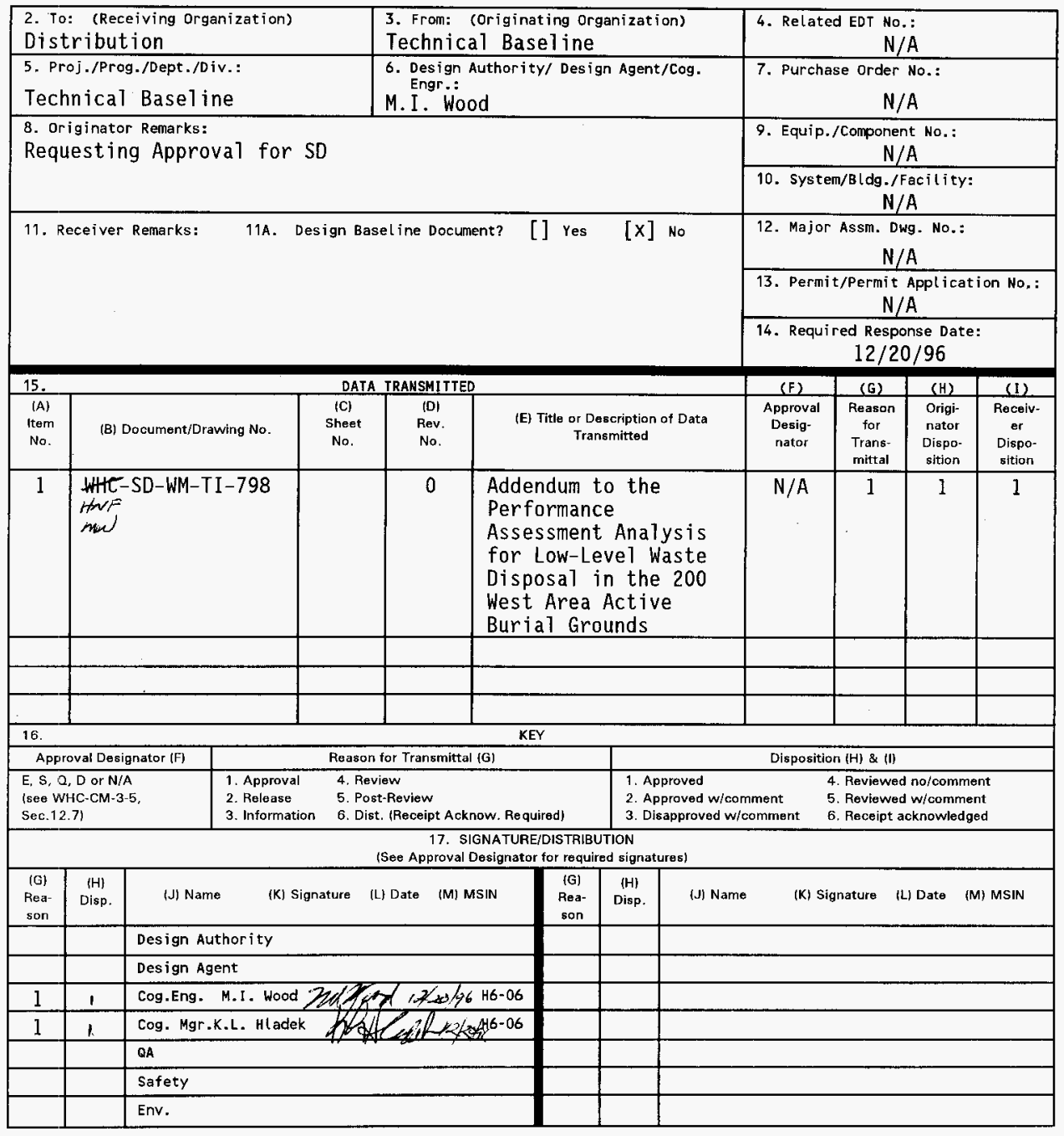

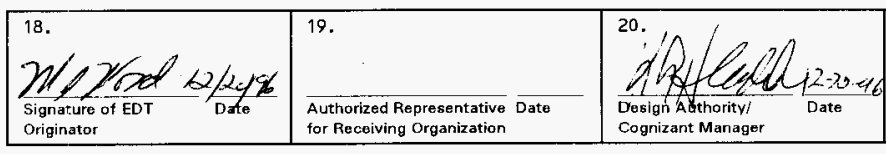

21. DOE APPROVAL (if required) Ctrl. No.

[] Approved

[] Approved w/comments

[] Disapproved w/comments 


\section{Addendum to the Performance Assessment Analysis for Low-Level Waste Disposal in the 200 West Area Active Burial Grounds}

\section{I. Wood}

Rust Federal Services of Hanford, Inc., Richland, WA 99352

U.S. Department of Energy Contract DE-AC06-87RL10930

$\begin{array}{lll}\text { EDT/ECN: } & 620426 & \text { UC: } 500 \\ \text { Org Code: } & 33410 & \text { Charge Code: A6V01 } \\ \text { B\&R Code: } & \text { EW } 3130020 & \text { Total Pages: } 73\end{array}$

Key Words: Performance Assessment, 200 West Area LLBG, DOE Order $5820.2 \mathrm{~A}$

Abstract: An addendum was completed to the performance assessment (PA) analysis for the active 200 West Area low-level solid waste burial grounds. The addendum includes supplemental information developed during the review of the PA analysis, an ALARA analysis, a comparison of PA results with the Hanford Groundwater Protection Strategy, and a justification for the assumption of 500 year deterrence to the inadvertent intruder.

TRADEMARK DISCLAIMER. Reference herein to any specific comercial product, process, or service by trade name, trademark, manufacturer, or otherwise, does not necessarily constitute or imply its endorsement, recommendation, or favoring by the United States Government or any agency thereof or its contractors or subcontractors.

Printed in the United States of America. To obtain copies of this document, contact: WHC/BCS Document Control Services, P.O. Box 1970, Mailstop H6-08, Richland WA 99352, Phone (509) 372-2420; Fax (509) 376-4989.
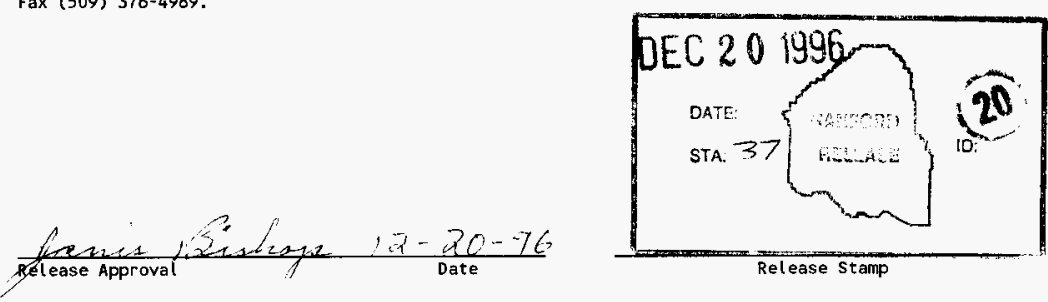

Approved for Public Release 


\subsection{INTRODUCTION}

Performance Assessment for the Disposal of Low-Level Waste in the 200 West Area Burial Grounds (Wood et al. 1995) has been completed in accordance with the requirements of Radioactive Waste Management, U.S. Department of Energy (DOE) Order 5820.2A (DOE 1988). The performance assessment has been reviewed extensively, first by the Peer Review Panel (PRP) for technical adequacy and completeness, then by the DOE for compliance with DOE Order 5820.2A. At the conclusion of its review process, the U.S. Department of Energy (DOE) issued a memorandum (Cowan 1996) stating conditional approval of the 200 West Area performance assessment (PA) analysis. A copy of the memorandum is provided as Appendix A. The following conditions had to be satisfied to gain complete approval.

- An addendum containing supplementary information provided to the Peer Review Panel during their review of the PA analysis had to be issued. This document fulfills that requirement. In all, three sets of information requests and responses were generated. The information in those sets is Appendix B of this document.

- The addendum (this document) also had to address the following topics (Cowan 1996), which are covered in Chapters 2 through 4 :

- "3. The site is to address the requirement for an ALARA analysis as required in the latter part of DOE Order 5820.2A, Chapter III, 3.a.(2). The detail of this analysis should be commensurate with the calculated doses.

- "4. The site is to document the rationale that was provided to reviewers during the course of the review for assuming intrusion into the Category 3 facility occurs at 500 years rather than 100 years as is assumed for the Category 1 facility.

- " 5 . The site is to discuss consistency of the performance assessment results with the requirements in the Hanford Site Ground Water Protection Plan and the Hanford Site Ground Water Remediation Strategy.

\subsection{ALARA ANALYSIS}

In accordance with Radiation Protection of the Public and the Environment, DOE Order 5400.5 (DOE 1993), the DOE is committed to reducing public exposure to radiation resulting from facility operations involving radioactive materials to a level that is as low as reasonably achievable (ALARA). The primary limit to the public is a total effective dose of $100 \mathrm{mrem} / \mathrm{yr}$ at the site boundary [Chapter II, paragraph 1.a.(1)]. DOE 5400.5 stipulates that the potential 
collective dose should also be considered for the population within $80 \mathrm{~km}$ of a central location at the site (Chapter II, paragraph 6.b). No collective dose limit is identified.

When applying ALARA requirements to the burial grounds, potential dose is most likely to occur as a result of groundwater contamination and subsequent use of that water. In the PA analysis, individual dose at a probable site boundary (either the Columbia River or the Central Plateau Compliance Boundary [DOE-RL 1994a, 1994b]) was not evaluated. However, individual dose was calculated at a hypothetical well $100 \mathrm{~m}$ downstream of the burial ground. Selection of this point of compliance was based on DOE guidance to the PA preparers (Hindman 1989). This location is closer to the source of radiation and so should yield a larger dose estimate than would be calculated at the likely site boundaries. Consequently, the individual dose estimates in the PA are considered conservative for comparison with the $100-\mathrm{mrem} / \mathrm{yr}$ dose limit.

The PA analysis included a collective dose estimate (Chapter 4, Section 4.4.3.2) that considered the effects of contaminated groundwater discharging into the Columbia River and subsequent use of the contaminated river water by a downstream population of 5 million people. The dose estimates from this analysis are considered applicable to the ALARA analysis.

The ALARA process has not previously been applied to facility operations that may cause environmental contamination and potential dose to the public long after closure of the facility. This section includes a simple, qualitative ALARA analysis that is consistent with the DOE guidance (Cowan 1996), which dictates that the complexity of the analysis should be "commensurate with the calculated doses." That is, if the calculated doses are small relative to the individual dose limit and the collective dose of the downstream population, ALARA principles should be satisfied by current waste management practices and an extensive analysis is not required.

The PA analysis does, in fact, predict relatively low doses even with the conservative assumptions chosen to maximize dose estimates to account for the uncertainty of natural conditions and future events affecting radionuclide release. Thus, the primary waste management option considered in this analysis is to continue with the current practices. Generally, waste is disposed of as received in trenches and will be covered either with a simple sparsely vegetated cover or a thicker, more vegetated cover to reduce the maximum possible infiltration. Some higher inventory wastes are stabilized by grouting or emplacement in a thick concrete cylinder. Realizing that further immobilization of waste can be achieved at greater cost, a second general option is considered in which a relatively undefined improved waste form is selected. This waste form further reduces the mobility of radionuclides at the source. Under these conditions, predicted leach rates into the soil column, groundwater concentrations, and individual doses are reduced.

\subsection{ALARA ANALYSIS FOR THE CURRENT DISPOSAL PRACTICE}

In the PA analysis, to estimate the individual dose at $100 \mathrm{~m}$ downstream of the facility, a final inventory of radionuclides likely to reach the unconfined aquifer was estimated. This 
estimated inventory was based on the current inventory at the time of the analysis and the projection of additional inventory based on projected waste volume (Table 4-27 in Wood et al. 1994). Projected dose could then be evaluated because dose is proportional to inventory. The projected individual drinking water dose was $0.13 \mathrm{mrem} / \mathrm{yr}$ at about 100 years after closure for Category 1 waste and $0.35 \mathrm{mrem} / \mathrm{yr}$ about 1,000 years after closure for Category 3 waste (Table 4-28 in Wood et al. 1995).

These doses are quite small compared to the 100-mrem/yr value; actual doses that would be received are realistically expected to be even smaller. First, if the doses are evaluated at the potential boundaries (either the Columbia River or some fence line between the 200 West Area and the Columbia River), they should be reduced because the boundaries are even farther (at least $10 \mathrm{~km}$ ) from the source than the 100-meter well. Second, the primary contributors to dose are ${ }^{129} \mathrm{I}$ for Category 1 waste (essentially $100 \%$ ) and ${ }^{129} \mathrm{I}$ and uranium for Category 3 waste (2/3 and $1 / 3$, respectively, of the total dose). The ${ }^{129} \mathrm{I}$ the inventory is highly uncertain and must be estimated because measurement is difficult and expensive. Conservatively high estimates based on process knowledge are expected because of the high volatility of iodine during processing. A conservatively high dose estimate also was calculated for uranium. The estimate assumes a much larger areal distribution of uranium in the waste volume than is likely.

A maximum collected dose of 1.6 person rem was estimated; the uranium contribution is essentially $100 \%$ of the estimate. This collective dose can be compared to a collective dose from natural radiation to the same population ( 5 million people). Assuming that natural radiation is about $300 \mathrm{mrem} / \mathrm{yr}$ (Dirkes and Hanf 1996), the total estimated collective dose is $1.5 \times 10^{6}$ person-rem/yr. Clearly, the contribution of disposed uranium to collective population dose is negligible. The estimate in the PA analysis (Wood et al. 1995) of collective dose from uranium is also very conservative. An unrealistically high distribution of uranium is assumed and no credit is taken for solubility effects. A more realistic estimate of uranium collective dose is 0.01 personrem or less, taking into account solubility and distribution effects defined in the PA analysis (Section 4.4.3.2).

\subsection{ALARA ANALYSIS FOR ENHANCED WASTE FORMS}

Projected doses are linearly dependent on inventory estimates and, because inventory projections are highly uncertain, the need for enhanced waste forms should be considered. The present PA approach evaluates the use of grout as an enhanced waste form, particularly for uranium (See Section 4.4.3.2), and the potential effects on projected dose to the individual. Although not directly specified in the analysis, grout is also considered as a potential waste matrix with a low diffusion coefficient that could be used to lower the release rate of other mobile radionuclides. The most commonly used waste form enhancement is placement of uraniumbearing waste in a thick concrete container. The use of low-diffusion waste matrices also is recommended for waste forms containing a high inventory of mobile radionuclides.

This option considers alternative waste forms that further limit the release of mobile radionuclides. For example, glass as a waste form has been extensively studied and is the 
preferred waste form for low-level waste generated by remediation of tank waste at the Hanford Site (Mann et al. 1996). Glass is likely to be as good if not better, a waste form than grout, which is now used in the burial grounds. However, some technical and practical considerations inhibit the use of glass as a waste form for solid low-level waste.

The need for waste form performance for waste disposed of in the burial grounds at the Hanford Site since the approval of DOE Order 5820.2A has been limited to occasional individual waste streams, primarily those including uranium. Of the $44,000 \mathrm{~m}^{3}$ of solid waste disposed of since September 26,1988 , only $424 \mathrm{~m}^{3}$ of uranium-bearing waste $(<1 \%)$ has been disposed of in concrete containers.

Grout is particularly well suited for immobilizing uranium because of its chemical properties. Two factors argue against selecting glass or another waste form material to treat this waste. First, another waste form is unlikely to substantially reduce uranium mobility compared to grout, so the reduction in potential dose would be negligible. Second, use of a glass-making facility or equivalent for very small volumes of waste would require finding an available facility, probably off site, to take the waste. We expect that the cost of waste treatment would be prohibitive under these conditions.

Other mobile radionuclides potentially requiring waste treatment occur less frequently than uranium in waste streams. If grout is unsuitable for other waste containing these mobile radionuclides, the alternative waste form option should be considered. Currently, knowledge is insufficient to make this evaluation. At present, a limited number of specific waste streams that contain sufficiently high inventories of mobile radionuclides requiring enhanced performance have been identified. Without this information and probably leach testing of waste forms with the real waste, the desired benefit of reduced dose cannot be quantified.

In addition to uncertainty about the potential for reduced radionuclide release, the potential difference in cost cannot be evaluated. It is expected that the cost of using glass or some other material will be higher than grouting costs based on the current use of grout materials in the burial grounds (either emplacement of preformed concrete boxes or grouting in place). Development costs (formulating the glass and release testing) and the fact that enhanced waste forms are used intermittently for relatively small volumes of waste suggest that additional expenses will be incurred.

\subsection{CONCLUSIONS}

The current waste disposal practices that are used to satisfy PA-derived practices satisfy the ALARA requirements. The dose estimates, both individual and collective, are small compared to identified limits or estimated doses from naturally occurring radiation. The PA accounts for the possible presence of waste containing high inventories of mobile radionuclides and evaluates methods for providing better immobilization of this waste. 
The option evaluated for improving facility performance was developing enhanced waste forms. These must be formulated and tested before use. A substantial reduction in potential dose is not expected, based on predicted radionuclide inventories or waste form properties. As waste is disposed of in the burial grounds, potential dose will continue to be evaluated as part of the PA maintenance program. Waste requiring treatment will be evaluated in terms of the most practical methods that are available for immobilizing the waste stream specific inventories.

\subsection{TIMES OF INTRUSION}

The rationale for assuming 500 years of delay after closure for intrusion into a Category 3 facility is provided in Wood et al. (1996). The primary argument is that the selection of an appropriate time of intrusion cannot have a technical basis, just as the expectation of an intrusion event cannot have a technical basis. To establish waste acceptance criteria, we assumed that intrusion will occur. Therefore, selection of appropriate parameter values such as the time of intrusion is largely based on consensus of opinion and previous actions. In this case, the rationale developed by the NRC to create a waste classification system for low-level waste disposal was adapted. The following discussion from Wood et al. (1996) is provided with some clarifications.

"For Category 3 waste, a combination of physical [burial ground, location] indicators and societal records is expected to exist to deter the inadvertent intruder for up to 500 years after closure. [The primary physical condition that would minimize the chance of early inadvertent intrusion into the Category 3 waste is the depth of burial and thickness of the final soil cover. Casual digging at the surface would not provide contact with the buried Category 3 waste.] The primary physical indication of the burial ground is the soil cover with associated visible markers, which may include signs and fences. The primary societal records include legal documents that describe the location and purpose of the facility. A strong technical basis cannot be provided for determining how long an inadvertent intruder can be assumed to be deterred from exhuming waste because of the unpredictability of human activities.

"The 500-year time period is based on the regulatory approach adopted by the NRC to develop the intruder protection classification system in $10 \mathrm{CFR} 61$. This approach is described in Oztunali et al. (1981). Three levels of intruder protection for disposal facilities were envisioned that provided increasing protection and corresponding increases in assumed deterrence time. The lowest level of protection was essentially no protection and intrusion occurred immediately after active institutional control was assumed to end. The intermediate level of protection assumed covering of waste with

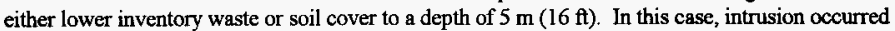
500 years after closure. The highest level of protection assumed solidification of waste by grouting or some other means and intrusion was assumed to occur 1,000 years after closure. The underlying assumption is that the disposal facility is recognizable to the inadvertent intruder during the assumed deterrence period either by providing a distinctive cover that maintains its shape through adequate stability of the waste volume or by a recognized stabilized waste form.

"In this analysis, we equate the Category 3 configuration with the intermediate level of protection. Under these conditions, the waste volume must be stabilized to the extent that the cover will maintain its shape. This requires that erosion control be adequate and subsidence minimal. A discussion of erosion control is provided in Section 2.2.2 [of Wood et al. 1996]. It was concluded that simulation of naturai vegetation conditions will prevent chronic erosion and that a cover would remain indefinitely unless disturbed by man. The use of concrete HICs, including backfilling between HICs 
with soil, stabilized waste forms, and void-space limitations in waste packages, is assumed to provide subsidence control. If it is determined during closure activities that additional void filling is required, technically feasible methods exist to enhance subsidence control (e.g., grout injection)."

\subsection{CONSISTENCY OF PA RESULTS WITH THE REQUIREMENTS IN THE GROUNDWATER MANAGEMENT PROTECTION PLAN AND THE HANFORD SITE GROUNDWATER REMEDIATION STRATEGY}

Groundwater contamination is widespread in the unconfined aquifer underlying the Columbia River Plateau. The source of radionuclide contaminants in groundwater has been discharge of contaminated liquids into the soil column throughout Hanford Site history. Cleanup of these existing contaminants are discussed in two documents: Hanford Site Ground Water Protection Management Plan (DOE-RL 1995a) and Hanford Sitewide Ground Water Remediation Strategy (DOE-RL 1995b). These documents focus almost entirely on the characteristics of the plumes and plans for removing existing contaminants from groundwater. Some of the initial sources are identified and future actions to aid groundwater cleanup are discussed briefly. The documents do not address the potential effects of solid low-level waste disposal on groundwater contamination. However, these documents will be revised in 1997 and will incorporate a discussion of solid waste sources.

To integrate the PA results that are used to estimate potential groundwater contamination and waste acceptance criteria developed to protect groundwater, we compare the PA approach with the groundwater remediation approach in the following three areas: Potential radionuclide specific concentration limits, points of compliance, and characteristics of present and potential groundwater contamination.

\subsection{COMPARISON OF CLEANUP GOALS}

Cleanup goals for contaminated groundwater are generally expressed as contaminantspecific concentrations at particular locations. In DOE-RL (1995a), 40 CFR 141, "National Primary Drinking Water Regulations," referred to as Drinking Water Standards, is identified as the primary source of concentration goals. These are identified in Table 1 (MCL-DWS) for the radionuclides capable of reaching the unconfined aquifer after leaching from solid waste disposed of in the burial grounds. However, 40 CFR 141 does not mention all radionuclides. In particular, uranium limits are missing and, because uranium plumes are present in the unconfined aquifer, a cleanup goal was needed. Although not identified in DOE-RL (1995a), the uranium concentration limit was taken from proposed drinking water standards in 56 FR 33050-33127, "Safe Drinking Water Act Proposed MCL for Radionuclides." The Hanford Site criteria for specific limits of radionuclides in groundwater are the combination of limits from 40 CFR 141 for ${ }^{129} \mathrm{I}$ and ${ }^{99} \mathrm{Tc}$ and the uranium limit from the proposed standard. 
Other radionuclide limits from 56 FR 33050-33127 are also shown in Table 1. These limits differ from those from 40 CFR 141, because of a recommended change in dose estimation method from critical organ dose to total effective dose, which considers dose to all organs and ranks the importance of each using a weighting system. In both cases, the concentration limits correspond to a drinking water dose of $4 \mathrm{mrem} / \mathrm{yr}$ when $2 \mathrm{~L}$ of water are consumed daily. The U.S. Environmental Protection Agency (EPA) developed these proposed standards in response to the recommended changes in dose estimation method. This change affects ${ }^{129} \mathrm{I}$ significantly and ${ }^{99} \mathrm{Tc}$ to a lesser extent. The increased allowable groundwater concentration for ${ }^{129} \mathrm{I}$ reflects the decreased emphasis on thyroid damage when evaluating total effective dose instead of critical organ dose.

Table 1. Radionuclide Specific Drinking Water Limit Groundwater Concentrations from Various Regulatory or Proposed Regulatory Requirements ( $\mathrm{pCi} / \mathrm{L})$.

\begin{tabular}{|l|c|c|c|c|c|}
\hline Dose Limit Sources & ${ }^{99} \mathrm{Tc}$ & ${ }^{129} \mathrm{I}$ & ${ }^{14} \mathrm{C}$ & ${ }^{79} \mathrm{Se}$ & Uranium \\
\hline MCL-DWS & 900 & 1 & 1939 & $\mathrm{ND}^{*}$ & $\mathrm{ND}^{*}$ \\
\hline MCL-Prop & 3790 & 21 & 3200 & $\mathrm{ND}^{*}$ & $20^{* *}$ \\
\hline Hanford Site Criteria & 900 & 1 & $\mathrm{ND}^{*}$ & $\mathrm{ND}^{*}$ & $20^{* *}$ \\
\hline PA & 4210 & 20 & 2610 & 660 & 23 \\
\hline
\end{tabular}

* None Determined

** This value is in units of $\mu \mathrm{g} / \mathrm{L}$ and the conversion to $\mathrm{pCi} / \mathrm{L}$ depends on the choice of specific activity.
MCL-DWS
40 CFR 141.16(b)-"Safe Drinking Water Act Maximum Contaminant Level for Radionuclides"
MCL-Prop 56 FR 33050-33127-"Safe Drinking Water Act Proposed MCL for Radionuclides"
Hanford Criteria A mixture of MCL-DWS and MCL-PROP adopted in DOE-RL(1995a) PA Performance Assessment limits Assuming 4-mrem/yr dose and internal dose factors from DOE/EH-0071 (DOE 1988)

Table 1 includes the concentration limits from the PA for comparison. Table 1 also includes a number of performance objective dose limits that are defined in DOE Order 5820.2A. These limits are provided to evaluate disposal facility performance, but none are specifically identified for drinking water or groundwater protection. Instead, a $25-\mathrm{mrem} / \mathrm{yr}$ all pathways performance objective is provided that includes consumption of contaminated groundwater and assumes the total effective dose equivalent method will be used when predicting dose. DOE Order 5820.2A defers to applicable federal, state, and local regulations for groundwater protection criteria. At the Hanford Site, no regulations exist that apply to groundwater plumes that may be derived from solid low-level waste burial grounds. Consequently, the 4-mrem/yr 
standard was selected and corresponding concentrations were derived using the total effective dose estimation method. The PA concentration limits are essentially the same as those found in 56 FR 33050-33127.

Because the Drinking Water Standard (DWS) and the proposed maximum concentration limits from the PA for ${ }^{99} \mathrm{Tc}$ and ${ }^{129} \mathrm{I}$ differ considerably, the potential for eventual groundwater plumes emanating from the solid low-level waste burial grounds with concentrations of these radionuclides exceeding the drinking water standard limits needs to be addressed. This discussion is provided in Section 4.4 .

\subsection{POINTS OF COMPLIANCE}

In DOE-RL (1994a), protection of the Columbia River is an immediate primary concern of stakeholders, the EPA, and the Washington State Department of Ecology. In this case, the points of compliance are clearly the Columbia River. The other concern is groundwater contamination beneath the interior of the Site, derived from liquid discharged in the 200 East and 200 West Areas, which are located on the Central Plateau (Figure 1). In this case, the ultimate points of compliance are not clearly defined. This ambiguity occurs because a general cleanup objective is to reduce contamination to the extent possible and to enhance the options of land use for as much land as possible. The best current estimate of compliance points that relate to the cleanup of these groundwater plumes is the boundary between the Central Plateau and other areas (Figure 1). This boundary is labeled the Central Plateau Compliance Boundary and is 10 to $15 \mathrm{~km}$ down gradient from the 200 West Area Burial Grounds. In the PA analysis, the point of compliance is arbitrarily defined as a well located $100 \mathrm{~m}$ downstream of the burial grounds.

\subsection{GROUNDWATER CONTAMINATION CHARACTERISTICS}

Distinct plumes have been mapped in the unconfined aquifer beneath the Central Plateau as a function of contaminant and location. The most widespread are the ${ }^{129} I$ and tritium plumes. No efficient method for removing these isotopes from groundwater is known; no resources have been committed to attempt retrieval of these isotopes. Several other plumes are characterized by chemically reactive, slow-moving isotopes (primarily ${ }^{137} \mathrm{Cs},{ }^{90} \mathrm{Sr}$, and plutonium near the B-5 reverse well in the Central Plateau). These plumes provide no immediate or long-term potential for either reaching the river or extending beyond the Compliance Boundary. The Groundwater Management Protection Plan (DOE-RL 1995a) calls for no further cleanup action. Finally, uranium and ${ }^{99} \mathrm{Tc}$ plumes are present; pump and treat remediation activities are recommended, along with the development of additional removal and containment techniques to prevent significant contamination of the aquifer beyond the Compliance Boundary. 
Figure 1. Hanford Future Site Uses Geographic Areas.

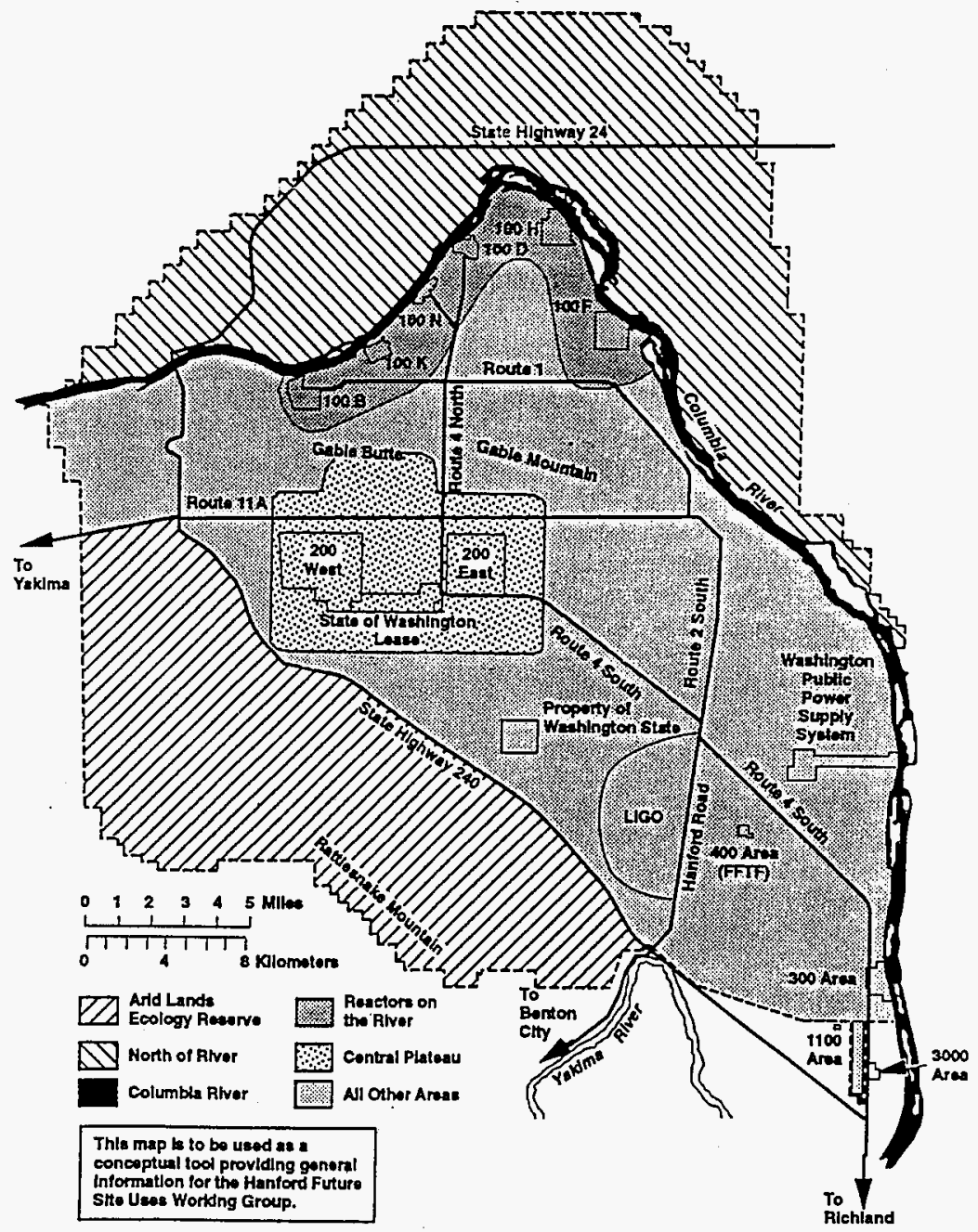

E9511047.3 
No contaminant plumes have been observed that can be attributed to the solid waste burial grounds. Based on the PA analysis, contaminant plumes from the 200 West Area solid waste burial grounds would not occur for at least 100 years. Of the radionuclides present in the solid low-level waste inventory, only uranium, ${ }^{99} \mathrm{Tc},{ }^{129} \mathrm{I},{ }^{14} \mathrm{C}$ and ${ }^{79} \mathrm{Se}$ are predicted to be mobile enough in the soil column to reach the unconfined aquifer. Only uranium and ${ }^{99} \mathrm{Tc}$ are known to be present in sufficient quantity to be of any concern. C-14 is present in large quantities, but most of the activity is present in activated metal and is highly immobilized. Enough ${ }^{129} \mathrm{I}$ and ${ }^{79} \mathrm{Se}$ may be present, but the actual activity of these isotopes in the waste is uncertain.

\subsection{POTENTIAL FOR GROUNDWATER CONTAMINATION DERIVED FROM SOLID WASTE TO EXCEED CLEANUP GOALS}

Table 2 provides estimates of peak concentrations resulting from the leaching of radionuclides from the projected solid waste inventory in the 200 West Area burial grounds. The peak concentrations are estimated to occur at a well east and $100 \mathrm{~m}$ downstream of the burial ground about 1,000 years after closure. Except for uranium, the groundwater concentration estimates are linearly dependent on inventory. Uranium concentrations depend on areal distribution assumptions. In this analysis, the projected inventory is assumed to be evenly distributed north-south, the direction perpendicular to groundwater flow. The concentrations in Table 2 assume no waste form performance except for uranium. In this case, release is controlled by solubility reactions from the natural soil geochemical conditions or Portland cement-based grout interactions with water.

Table 2. Estimated Peak Groundwater Concentrations at a Well $100 \mathrm{~m}$ Downstream of the 200 West Area Low-Level Burial Grounds.

\begin{tabular}{|l|c|c|c|c|c|c|}
\hline & ${ }^{99} \mathrm{Tc}$ & ${ }^{129} \mathrm{I}$ & ${ }^{14} \mathrm{C}$ & ${ }^{79} \mathrm{Se}$ & $\begin{array}{c}\text { Uranium } \\
\text { nongrouted }\end{array}$ & $\begin{array}{c}\text { Uranium } \\
\text { grouted }\end{array}$ \\
\hline Peak Concentration (pCi/L) & 10.3 & 1.93 & 31.6 & - & 0.87 & 0.018 \\
\hline MCL-DWS & 900 & 1 & 1939 & ND & ND & ND \\
\hline MCL-PROP & 3790 & 21 & 3200 & ND & ND & ND \\
\hline
\end{tabular}

None Determined

MCL-DWS

MCL-Prop
40 CFR 141.16(b)_-"Safe Drinking Water Act Maximum Contaminant Level for Radionuclides"

56 FR 33050-33127_-"Safe Drinking Water Act Proposed MCL for Radionuclides" 
To evaluate the significance of these estimates to cleanup goals, the Drinking Water Standard limits and the PA limits must be compared by radionuclide. Uranium and ${ }^{79} \mathrm{Se}$ cannot be compared because they are not considered in the DWS standard. However, if the proposed standard is assumed, as it is in DOE-RL (1994a), the PA limit is slightly lower than the cleanup standard. Consequently, we conclude that any release of ${ }^{79} \mathrm{Se}$ or uranium from the burial ground will not exceed allowable limits. The estimated long time to peak concentration should eliminate the possibility of overlap with existing plumes containing these radionuclides.

Potentially significant inconsistency between the proposed concentration limits in the Groundwater Management Protection Plan and the PA target limits does occur for ${ }^{129} \mathrm{I}$ and ${ }^{99} \mathrm{Tc}$, assuming that the DWS limits will be the final agreed-on standard. The higher ${ }^{99} \mathrm{Tc}$ and ${ }^{129} \mathrm{I}$ peaks allowed in the PA analysis could result in the disposal of unacceptably high concentrations of these isotopes in burial ground waste. However, several factors argue against this possibility.

First, the assumed point of compliance for groundwater protection (the Columbia Plateau Boundary) is 10 to $15 \mathrm{~km}$ farther downstream than the $100-\mathrm{m}$ downstream well assumed in the PA. Although a specific analysis has not been done, the additional distance from the downstream well to the compliance point and the limited source for these radionuclide are expected to substantially dilute the estimated peak concentration of any radionuclide by the time it reaches the Columbia Plateau Boundary. A composite analysis is being prepared that will quantitatively compare groundwater concentrations at a $100 \mathrm{~m}$ well and the Central Plateau Compliance Boundary.

Second, the peak concentrations are estimated under conservative conditions. Little credit is taken for the effects of dilution and all inventories are assumed to be leached simultaneously. The estimated peak groundwater concentrations are expected to be well above realistic levels of contamination.

For ${ }^{99} \mathrm{Tc}$, the estimated inventory leads to peak concentrations that are well below any of the proposed standards and are expected to satisfy any of the long-term cleanup goals. One activity of the PA maintenance program will be to track mobile radionuclides disposed of in the burial grounds and predict potential groundwater contamination. If this inventory projection is unrealistically low, steps can be taken to specifically immobilize ${ }^{99} \mathrm{Tc}$ or prevent further ${ }^{99} \mathrm{Tc}$ disposal as needed.

The predicted ${ }^{129} \mathrm{I}$ concentration does exceed the DWS goal. However, we do not anticipate that the finally determined acceptable limit will be exceeded because of the analytical conservatisms discussed earlier. In addition, the predicted peak concentration for ${ }^{129} \mathrm{I}$ in Table 2 depends on the predicted final inventory. The actual ${ }^{129} \mathrm{~T}$ inventory in solid waste is uncertain because ${ }^{129}$ I frequently occurs in trace amounts that cannot be measured. Consequently, estimates of activity in waste are based on process knowledge using conservative assumptions. Scaling factors generally do not account for the known volatility of ${ }^{129} I$ in processes that generate waste, therefore we anticipate that any projected inventory will be larger than a real inventory. Finally, laboratory sorption data for ${ }^{129} \mathrm{I}$ (Kaplan et al. 1995) suggest that Kd values for ${ }^{129} \mathrm{I}$ may be in 
excess of $1 \mathrm{ml} / \mathrm{g}$. In the PA analysis, no ${ }^{129} \mathrm{I}$ sorption was assumed to occur when estimating the peak concentration shown in Table 2 . If a $\mathrm{Kd}$ value of $1 \mathrm{ml} / \mathrm{g}$ is assumed, peak concentration values are predicted to decrease by a factor of 15 at the $100-\mathrm{m}$ downstream well. This is well below the drinking water standard of $1 \mathrm{pCi} / \mathrm{L}$.

\section{S.0 REFERENCES}

56(138) FR 33050, 1991, "National Primary Drinking Water Regulations: Radionuclides, Notice of Proposed Rulemaking," Federal Register, Volume 56, pp. 33050-33127.

40 CFR 141, "National Primary Drinking Water Regulations, " Code of Federal Regulations, as amended.

Dirkes, R. L., and R. W. Hanf, 1996, Hanford Site Environmental Report for 1995 , PNNL-11139, Pacific Northwest National Laboratory, Richland, Washington.

DOE, 1988a, Radioactive Waste Management, DOE Order 5820.2A., U.S. Department of Energy, Washington, D.C..

DOE, 1988b, Internal Dose Conversion Factors for Calculation of Doses to the Public, DOE/EH-0071 (DE88-014297), U.S. Department of Energy, Washington, D.C..

DOE, 1993, Radiation Protection of the Public and the Environment, DOE Order 5400.5, U.S. Department of Energy, Washington, D.C.

DOE-RL, 1995a, Hanford Site Ground Water Protection Management Plan, DOE/RL-89-12, Rev. 2, U.S. Department of Energy, Richland Operations Office, Richland, Washington.

DOE-RL, 1995b, Hanford Sitewide Ground Water Remediation Strategy, DOE/RL-94-95, Rev. 0, U.S. Department of Energy, Richland Operations Office, Richland, Washington.

Cowan, S. P, 1996, Conditional Acceptance of the Hanford 200 West Area Burial Ground Performance Assessment, letter to C. Hansen, U.S. Department of Energy, Richland Operations Office, dated June 27, 1996, U.S. Department of Energy, Washington, D.C.

Hindman, T. B., Jr., 1989, Clarification of Requirements of DOE Order 5820.2A, letter to Distribution, U.S. Department of Energy, dated February 28, 1989, U.S. Department of Energy, Washington, D.C.

Kaplan, D. I. and R. J. Serne, 1995, Distribution Coefficient Values Describing Iodine, Neptunium, Selenium, Technetium, and Uranium Sorption to Hanford Sediments, PNL-10379, Sup. 1, Pacific Northwest Laboratory, Richland, Washington. 
Oztunali, O. I., B. C. Re, P. M. Moskowitz, E. D. Picazo, and C. J. Pitt, 1981, Data Base for Radioactive Waste Management, NUREG/CR-1759, Vol. 3, U.S. Nuclear Regulatory Commission, Washington, D.C.

Wood, M. I., R. Khaleel, P. D. Rittman, A. H. Lu, S. H. Finfrock, R. J. Serne, and K. J. Cantrell, 1995, Performance Assessment for the Disposal of Low-Level Waste in the 200 West Area Burial Grounds, WHC-EP-0645, Westinghouse Hanford Company, Richland, Washington.

Wood, M. I., R. Khaleel, P. D. Rittman, A. H. Lu, S. H. Finfrock, T. H. DeLorenzo, and D. U. Garbrick, 1996, Performance Assessment for the Disposal of Low-Level Waste in the 200 East Area Burial Grounds, WHC-SD-WM-TI-730, Rev. 0, Westinghouse Hanford Company, Richland, Washington. 
HNF-SD-WM-TI-798, Rev. 0

This page intentionally left blank. 
HNF-SD-WM-TI-798, Rev. 0

APPENDIX A

DOE MEMORANDUM OF CONDITIONAL ACCEPTANCE OF THE PA ANALYSIS 
HNF-SD-WM-TI-798, Rev. 0

This page intentionally left blank. 
- anr Jund 27. 1996

mir Ta

anw on: $84-35$

-axer Condtional Acceptance of the Hanford 200 West Area Burtal Ground Perforiance Assessment

. Tor Charles Hansien, Richland Operationis Office

Headquarters (HA) hat conducted a revitew of the "Performanca Assessment for the Disposal of Low-Lovel Maste in the 200 West Area Burtal Grounds." Novenber- 1994 far conpliance with DOE Order. 5820:2A: In the course of this reviey, the office of Waste Managenent (EN-30) raquested a review of the performince assessment by the Peer Review Pand (PRP). . Based on input from the PRP and the evaluation by $\mathrm{HQ}$ staff, the perforance assassment. is. conditionally accepted. A conpliance evaluation of the performance assessment 1s. Included as an attachment to this momorandun. By complying with the conditions bulow, you are authorized for. Interim operations of the 200 West Area Burfal Grounds until 1ssuance of a disposal authorization stateant.

Consistent with the "Defense Muclear Fucllities. Safaty Board (ONFSB) Recomendution 94-2 Inpluentation Plan, Revision 1," (Aprl1 1996). ful] approval of the sperformance assessment will not be possible until the completion of a composite analysis mich evaluates the potential offsite radiological 1macts of the 200 West Area burial grounds in conjunction vith other radiaactive sources that will remain at the Hanford Site. Upon satisfactory completion of the composite analysis and approval by $H Q_{\text {: }}$ this performance assessment will be approved and disposal authorization statement issued.

The subject porformance assessment is hereby conditionally accepted by : EM-30. The conditions that must be met are:

1. The Richland Operations office is to submit a composite analysis which includes the 200 West Ara Burlal Grounds by Decenber 31, 1997, as comitted to in the DKFSB Recomendation 94-2 Inplementation Pian. Revision 1.

2. Hixiford must inplement the controls documented in the memarandum June M. Hennig to J. A. Turl, "Submittal of Additional Information on the 200 Hest Area Bur1a1 Ground Performance Assessnent, " January 19, 1995, rosponse 1.e. to ensure that the conditions avaluated. In the performance assessment are pot. The Richland. . Operations office is to assure that these contrals are in place. by. Deceaber 31, 1996.

3. - The site is to address the requirament for an ALARA analysts is requited In the latter part of DOE Order 5820.2A, Chaptor III, 3.1.(2). The 


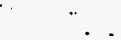

detall of this analysis should be comensurate with the calculated doses:"

4. The site ts to docuant the rationale that was provided to reviejurs $\because$ during the course of the reviow for assuming intrusion into the category 3 facility occurx at 500 years rather than ibo years is is assumed for the category 1 facility.

5. The site is to discuss consistency of the performance assessment results Wh the requirements in the "Hanford Sito Ground Uater Protection Plan"

- and the "Hanford Site Ground yater Remediation Stratogy."

6." An addendum to tife parforinance assessment is 1 to be issued by Deciember 31, 1996. The addendum ts to include the additional information developed by the site in response to numbors 3,4 , and 5 above and the Information irequests fron the PRP. The addendum mist be distributed to all known holders of the periformance assessment. The purpose of this

condizion is to onsure that the documentation that yas the basis for.HOs' acceptance is rendily: avallable to any party interested in tho perforoance assexsuent. $\because$

The site is responstble for maintaining this performance assessment in accordance with the morandun, Interia Policy on Rogulatory Structure for Low-LeveT" Radioactive Waste Hanagement and Disposal" (July 21, 1995). This. Involves the conduct of fleld data gathering needed to improve confidence in the analyses.

If your staff has any questions regarding the conditlonal acceptance of this performance assessment and the process for getting full approval, they should contact Vingil Lowery of ay staff on (301) 903-7142.

Attuchment

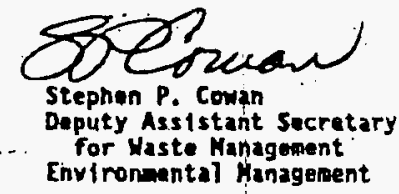

BST Whang COPY 
HNF-SD-WM-TI-798, Rev. 0

\begin{abstract}
APPENDIX B
SUPPLEMENTAL INFORMATION PROVIDED TO THE PEER REVIEW PANEL DURING FINAL REVIEW OF THE 200 WEST AREA PERFORMANCE ASSESSMENT ANALYSIS
\end{abstract}


HNF-SD-WM-TI-798, Rev. 0

This page intentionally left blank.

B-ii 
HNF-SD-WM-TI-798, Rev. 0

\section{APPENDIX B}

SUPPLEMENTAL INFORMATION PROVIDED TO THE PEER REVIEW PANEL DURING FINAL REVIEW OF THE 200 WEST AREA PERFORMANCE ASSESSMENT ANALYSIS

During the final review of the performance assessment (PA) analysis, the Peer Review Panel (PRP) requested additional information to assist them in their review of the PA analysis. Three separate requests for information were issued. This appendix contains these requests and the responses from the PA authors. 
DATE:

REPLY TO

ATTH OF:

SUBUECT:

\author{
JAN 191995
}

WPD:AKC 95-SWT-033

SUBMITTAL OF ADDITIONAL INFORMATION ON THE 200 WEST AREA BURIAL GROUND PERFORMANCE ASSESSMENT

To: J. A. Turi, Director

Office of Program Integration; EM-33--

Reference: E. L. Wilhite, PRP Chairman, to J. M. Hennig,

RL, "Request for Additional Information on

the Hanford 200-W PA," SRT-HED-94-0121, dated

December 5, 1994.

The referenced letter requested additional information on the 200 West Area Burial Ground Performance Assessment. To expedite the process, this information has been sent via Federal Express to the members of the Peer Review PaneT. In addition, any comments that EM-30 has on the subject document would be appreciated. Please address any questions that you may have on this subject to A. K. Crowel7, of my staff, on (509) 372-2346.

\title{
Attachment
}

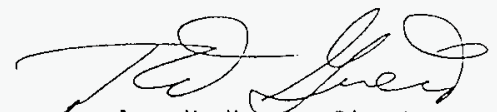

cc w/attach:

E. L. Wilhite, WSRC

W. R. Hansen, LANL

D. W. Layton, LLNL

R. L. Nitschke, EG\&G Idaho

G. J. Shott, REECo

D. H. Lee, ORNL

S. M. Neuder, Battelle

R. Martinez, EM-363

K. W. Owens, SAIC

G. J. Duggan, EM-332 
HNF-SD-WM-TI-798, Rev. 0

9407538B Rl

Attachment 1

Page 1 of 16

Comment: 1.a. A more complete discussion of the development of groundwater-based limits for the several burial grounds considered in this PA, including their derivation from the modeling of a $1 \mathrm{~m} \times 20 \mathrm{~m}$ trench segment and the effect of trench width and length. The discussion should include the consideration of varying trench length on the control of the inventory of long-lived, mobile radionuclides

Response: The 200 West Area LLBG consists of five active burial grounds. Each burial ground is a series of individual trenches in various stages of use (e.g., trenches are filled, partially filled, constructed, but not used, or proposed but not yet constructed). In addition, trenches are of different lengths( ${ }^{\sim} 100$ to 300 $\mathrm{m})$ and widths $(\sim 3$ to $100 \mathrm{~m})$. To evaluate radionuclide release and potential dose from groundwater contamination for this variety of conditions and to establish usable waste acceptance criteria, a flexible approach was needed. Flexibility was achieved by evaluating radionuclide release from a small representative slice of a trench $(1 \mathrm{~m}$ by $20 \mathrm{~m})$, and extrapolating the results to larger waste volumes from a whole trench up to the entire 200 West Area LLBG. The significant aspects of the conceptual model affecting dose estimates and the rationale for the extrapolation process is summarized in this discussion.

The conceptual model for evaluating groundwater contamination by . radionuclides released from the disposal facility consists of a two dimensional cross section of a disposal trench that is oriented parallel to the primary direction of groundwater flow. The width of the trench perpendicular to the cross section is any length. The radionuclide distributions in the waste volume are represented as (1) a total inventory that is homogeneously distributed over the waste volume in the direction perpendicular to flow, or (2) a constant concentration throughout the waste volume. The selected representation is dependent on the assumed leaching mechanism. In the total inventory representation, the leaching mechanism is either advection or diffusion controlled. In the constant concentration representation, the leaching mechanism is solubility controlled. These representations of radionuclide distribution are necessary to allow the application of the dose estimate results to variable size trenches and waste volumes. Further discussion of this hypothesis is provided below.

To make this representation site specific, it is assumed that the directions perpendicular and parallel to flow are north-south and east-west, respectively (see Figure 2-15 in the document). The length of trench parallel to flow is 20 m. In order to facilitate extrapolation of the results, it has been assumed that either (l) a unit quantity $(1 \mathrm{C} /$ ) of a given radionuclide is present in every partial waste volume with a 1 m width north-south, or (2) the concentration in waste volume water is $1 \mathrm{Ci} / \mathrm{m}^{3}$. The $1 \mathrm{~m}$ wide, $20 \mathrm{~m}$ long waste volume can be thought of as a representative slice. The numerical representation of the partial disposal system (i.e., trench slice, surrounding soil colunn and unconfined aquifer) was extended to a point $100 \mathrm{~m}$ downstream from the eastern edge of the trench. 
Given these assumptions, a generic set of calculations was completed. The effects of retardation and radioactive decay were not considered when calculating radionuclide flux at the trench soil-column boundary. Retardation effects were assumed to occur in the soil column and influence groundwater concentrations. The effects of radioactive decay were factored into the peak concentration estimate by calculating the reduction of inventory during the time required to reach the peak concentration. The primary output from the radionuclide release and transport model was an estimate of radionuclide concentrations in the groundwater as a function of time. The numerical approach allowed an estimate of radionuclide concentrations at any point in the aquifer out to $100 \mathrm{~m}$ downstream.

To compare estimated dose with the performance objectives, the peak concentrations at a hypothetical we $11100 \mathrm{~m}$ downstream were used to calculate dose. Peak dose is directly proportional to peak concentration. These results were then extrapolated to (1) larger areas of individual trenches and, in some cases, the entire facility, and (2) a variety of radionuclides with variable inventories or concentrations.

The ability to extrapolate the results of radionuclide release estimates to larger waste areas, waste volumes, and variable radionuclide inventories was based on the construction of the conceptual model and the characteristics of the facility and the site. Accurate extrapolation was achieved by properly selecting the physical orientation of the representative slice and representing the larger volume in the same orientation as the representative slice. In essence, if the waste volume is perpendicular to the general direction of groundwater flow, the calculated dose is proportional to (1) the physical dimensions of the facility and (2) the initial radionuclide inventory or the initial radionuclide concentration (in the case of solubility controlled release).

This orientation creates two conditions that lead to the proportionality relationships. First, all of the radionuclide flux from the disposal facility is captured by the volume of groundwater as it passes underneath the disposal facility and migrates toward the $100 \mathrm{~m}$ we 11 . This is a reasonable assumption because the model is two dimensional and no loss of radionuclides by dispersion that is transverse to the direction of flow is permitted. Because the entire flux is ultimately captured and contributes to the groundwater concentration over time and the groundwater velocity is high relative to the vertical downward percolation, the peak concentration is proportional to the total radionuclide flux independent of the length of the trench. Second, the volume of groundwater that captures the radionuclide flux released into the aquifer is proportional to the width of the waste volume that is perpendicular to the direction of groundwater flow. Consequently, if the width of the waste volume is increased and the total radionuclide flux from that waste volume is unchanged, the groundwater radionuclide concentrations at any given time will be reduced proportionately to the relative increase in width. Conversely, if the flux per unit width is held constant, the groundwater concentrations will also remain the same. 
To extrapolate the results from the representative slice to larger waste areas and volumes four types of extrapolation must be considered. These include (1) variability in the trench width north-south, (2) variability in the trench length east-west, (3) variability in the radionuclide isotopes in the inventory and the activities or solubility values of the individual radionuclides in the initial inventory, as appropriate, and (4) combined effects. The method of extrapolation is illustrated in the following examples:

North-south variability - The north-south trench width of the representative slice is $1 \mathrm{~m}$. If the north-south width of the actual trench is $10 \mathrm{~m}$, the peak close estimate is equivalent to that determined for the representative slice if the $10 \mathrm{~m}$ trench can be considered as ten parallel and adjacent $1 \mathrm{~m} \mathrm{~s}$ lices. This occurs when the total radionuci ide flux from the $10 \mathrm{~m}$ trench is 10 times that assumed for the 1 meter trench. Conversely, if the total radionuclide flux remains the same in the $10 \mathrm{~m}$ trench as in the $1 \mathrm{~m}$ trench, the volume of diluting groundwater increases by a factor of 10 and the peak dose estimate is decreased by a factor of 10 .

East-west variability - The east-west trench length of the representative slice is $20 \mathrm{~m}$. If the north-south trench width is kept at $1 \mathrm{~m}$ and the east-west trench length of interest is $40 \mathrm{~m}$, the peak dose will remain essentially constant as long as the total radionuclide flux from the total waste volume is unchanged because that flux is being captured by the same volume of diluting groundwater. Actually, a small decrease in peak dose will be calculated as the length of the trench increases because of small dispersion effects in the direction of flow. Conversely, if the radionuclide flux doubles along with the doubling of the trench length, the peak dose estimate will also double.

Radionuclide specific inventory or concentration variability - The waste volume orientation discussion indicates that proportional ity relationships are dependent on radionuclide flux at the trench-soil column boundary. Radionuclide flux from the trench that results in the peak concentration in the groundwater is, in turn, proportional to the initial concentration. However, the initial concentration is controlled differently, depending on the choice of radionuclide release mechanism.

When advective flux or diffusional flux is assumed, flux is directly proportional to the initial radionuclide concentration. Because all of the radionuclide flux is captured in the aquifer volume that contributes to well water dose, the distribution of the inventory in the waste volume does not impact overall flux significantly. An inventory can be considered as if it were homogeneously distributed over the waste volume as an "average concentration". Thus, as the initial inventory increases or decreases, then the "average concentration" increases or decreases proportionately. In this manner, the initial concentration is proportional to the initial inventory and peak dose is also proportional to initial inventory when advective or diffusive release is assumed. As an example, if the radionuclide inventory in the representative slice were $2 \mathrm{Ci}$ instead of the $1 \mathrm{Ci}$ inventory assumed, the peak dose estimate would be doubled. 
94075388 R1

Attachment 1

Page 4 of 16

Conversely, when the release is solubility controlled, the radionuclide flux is dependent on the chemical conditions, not the inventory. The distribution of the radionuclide in the waste volume between water and the precipitating solid that contains the radionuclide is variable because only the solution concentration is fixed by the chemical conditions of the environment. As long as there is a sufficient mass of the precipitating solid containing the radionuclide to maintain the solubility concentration in the waste volume, radionuclide flux will be unchanged. Increased radionuclide inventory with no change in chemical conditions simply results in increased mass of the precipitated solid without changing the solution concentration. If chemical conditions change and the solubility changes occur, the peak dose will change proportionally. For example, if the solubility controlled concentration is 2 $\mathrm{Ci} / \mathrm{m}^{3}$ rather than the $1 \mathrm{Ci} / \mathrm{m}^{3}$ assumed in the generic case, the peak dose estimate would be doubled.

Combined effects - Both the orientation of the waste volume and the selected Teaching mechanism influence the peak groundwater concentration and therefore, the peak dose estimate. The dependence of radionuclide flux on inventory versus concentration also affects the method of extrapolation of results to variable waste volumes, dimensions parallel and perpendicular to flow, and inventories. The following two examples illustrate these relationships when radionuclide flux is proportional to inventory (advective and diffusive release). First, if the $1 \mathrm{Ci}$ of the radionuclide that is assumed to be present in the representative trench is extrapolated to a trench of $40 \mathrm{~m}$ length east-west and $1 \mathrm{~m}$ width northsouth, the peak dose estimate is the same as that calculated for the representative trench. This is true because the radionuclide flux and the volume of diluting groundwater remains the same. Second, if the $\mathrm{l} C \mathrm{i}$ of the radionuclide that is assumed to be present in the representative trench is extrapolated to a trench of $20 \mathrm{~m}$ length east-west and $2 \mathrm{~m}$ width north-south, the peak dose estimate would be half that calculated for the representative trench. This is true because the total radionuclide flux remains the same but volume of diluting groundwater is doubled. In summary, peak dose is sensitive to distribution of the inventory in the direction perpendicular to flow, but not to the distribution of the inventory in the direction parallel to flow.

The extrapolation process is changed when flux is proportional to constant concentration dictated by chemical conditions. This is illustrated by two examples. First, if the waste volume water concentration is $1 \mathrm{Ci} / \mathrm{m}^{3}$ and the waste volume is present over a $1 \mathrm{~m}$ width of trench north-south and a $40 \mathrm{~m}$ length of trench east-west instead of the representative trench (1 m width of trench north-south and $20 \mathrm{~m}$ length of trench east-west), the peak dose estimate is doubled compared to the base case. This occurs because twice as much flux is being discharged into the same volume of diluting groundwater. Second, if the waste volume water concentration is $1 \mathrm{Ci} / \mathrm{m}^{3}$ and the waste volume is present over a $2 \mathrm{~m}$ width of trench north-south and a $20 \mathrm{~m}$ length of trench east-west instead of the representative trench $(1 \mathrm{~m}$ width of trench north-south and $20 \mathrm{~m}$ length of trench east-west), the peak dose estimate is the same relative to the base case. This occurs because the ratio of diluting groundwater to the flux is maintained. In other words, while the volume of diluting groundwater is doubled, 
so is the total radionuclide flux. In summary, peak dose is sensitive to distribution of the radionuclide in the direction parallel to flow, but not to distribution of the inventory in the direction perpendicular to flow.

The $P A$ results indicate that only long-lived mobile radionuclides potentially contaminate groundwater within the 10,000 yr compliance period. For these radionuclides, neither decay nor sorption and retardation in the soil column or unconfined aquifer have any influence on the dose estimates or waste acceptance criteria. Of these, only $U$ release is considered to be a candidate for solubility controlled release, either in soil or grout. This means that potential dose is calculated with respect to the encapsulation of waste in grout and the distribution of uranium waste in the direction parallel to flow. The leaching of the other radionuclides (e.g., ${ }^{99} \mathrm{TC},{ }^{14} \mathrm{C},{ }^{129} \mathrm{I}$ ) are either advection controlled or diffusion controlled. Thus, potential dose and waste acceptance criteria are dependent on the absence or presence of a diffusion controlling waste form and the distribution of the inventory in the direction perpendicular to flow.

Comment 1.b. Clarification of the development of groundwater-based limits for radionuclides, such as uranium, which have a chemical solubility limit under disposal limits.

Response: The response to this comment has been incorporated into the response to the previous comment where the effects of solubility control on dose estimates are provided.

Comment 1.c: A discussion of how WAC will be derived from the groundwater-based inventory 1 imits calculated in the $P A$ and a discussion of how the groundwaterbased WAC will be integrated with the intruder-based WAC.

Response: In the PA analysis, it was determined that the intruder could potentially receive a dose from all radionuclides with half lives greater than $5 \mathrm{yr}$. Because doses were linearly related to initial concentration, disposal limits take the form of concentration limits. In addition, it was determined that the offsite individual could potentially receive a significant dose from groundwater contaminated by a small set of long-lived, mobile radionuclides. Because doses from these radionuclides were linearly proportional to total inventory or constant concentration ( in the case of solubility control of release) and physical orientation of the disposed waste, disposal limits take the form of total activity ( $\mathrm{C}$ ) or solubility values $\left(\mathrm{Ci} / \mathrm{m}^{3}\right)$ per dimension of the waste volume relative to the direction of groundwater flow. The pertinent waste volume dimension is width of waste volume perpendicular to flow if radionuclide release is advection or diffusion controlled, and parallel to flow if radionuclide release is solubility controlled. For these radionuclides, both the groundwater and intruder scenario driven criteria must be satisfied.

As described above, the potential doses are proportional to either (1) concentration (intruder) or (2) total inventory or solubility values (groundwater use by the offsite individual). The two sets of limits are not directly 
HNF-SD-WM-TI-798, Rev. 0

9407538B RI

Attachment 1

Page 6 of 16

comparable. To ensure acceptable disposal of wastes containing long-lived, mobile radionuclides, the two types of criteria must be reconciled by taking into account the conditions under which potential doses were calculated. Also, additional actions must be taken to ensure that these wastes are disposed properly. Information currentiy provided by the generator is sufficient to ensure that waste acceptance criteria are satisfied for the intruder limits. To satisfy the groundwater limits, additional information and/or waste treatment may be required of the generator. Also, action by the disposal facility operator may be needed to satisfy the groundwater limit criteria. This occurs because (1) groundwater limits are, in effect, more restrictive than intruder limits for these radionuclides, (2) positioning of the waste in the facility affects the potential dose calculations and (3) waste form performance may be required to dispose of some wastes with sufficiently high inventories of these wastes.

To illustrate the observation that groundwater limits are effectively more restrictive than intruder limits for these radionuclides, both intruder and groundwater limits are provided in the table below. The groundwater limits are applicable to the case where no waste form performance is assumed and the Ci limit applies to any waste volume whose north-south dimension is $1 \mathrm{~m}$. Note that the magnitude of the intruder and groundwater values are similar even though the units of measure are different. This means that relatively few containers of waste containing the intruder limit concentration are needed to exceed the groundwater inventory limit. For example, if a waste stream packaged in 55 gallon drums (volume $-0.22 \mathrm{~m}^{3}$ per drum) contains ${ }^{99} \mathrm{Tc}$ at the maximum Category l intruder 7 imit $\left(2.3 \times 10^{-2} \mathrm{Ci} / \mathrm{m}^{3}\right)$, only 11 containers at a total volume of $2.4 \mathrm{~m}^{3}$ are needed to exceed the Category 1 groundwater $1 \mathrm{imit}$. However, the waste volume over which the groundwater limit is applied could be on the order of 1000 $\mathrm{m}^{3}$ (e.g., a waste volume that is $1 \mathrm{~m}$ wide in the north-south direction, $300 \mathrm{~m}$ long in the east-west direction and $3.3 \mathrm{~m}$ thick). Consequently, it is conceivable that the groundwater limits could rather easily be exceeded in a given waste volume even if intruder 7 imits were satisfied. 
9407538B Rl

Attachment 1

Page 7 of 16

Table 1. Comparison of Intruder and Groundwater Limits for Long-Lived Mobile Radionuclides

\begin{tabular}{|c|c|c|c|c|}
\hline Radionuclide & $\begin{array}{l}\text { Intruder } \\
\text { Limits }\left(\mathrm{Ci} / \mathrm{m}^{3}\right) \\
\text { Category } 1\end{array}$ & $\begin{array}{l}\text { Intruder } \\
\text { Limits }\left(\mathrm{Ci} / \mathrm{m}^{3}\right) \\
\text { Category } 3\end{array}$ & $\begin{array}{l}\text { Groundwater } \\
\text { Limits (Ci) } \\
\text { Category } 1\end{array}$ & $\begin{array}{l}\text { Groundwater } \\
\text { Limits (Ci) } \\
\text { Category } 3\end{array}$ \\
\hline${ }^{1 / 4} \mathrm{C}$ & 0.091 & 21 & 0.033 & 0.25 \\
\hline${ }^{36} \mathrm{Cl}$ & $6.4 \times 10^{-4}$ & 0.14 & 0.023 & 0.18 \\
\hline${ }^{79} \mathrm{Se}$ & 0.51 & 110 & 0.0085 & 0.063 \\
\hline${ }^{99} \mathrm{TC}$ & 0.023 & 5.0 & 0.053 & 0.40 \\
\hline${ }^{129} 1$ & 0.0085 & 1.8 & 0.00025 & 0.0019 \\
\hline${ }^{197} \mathrm{Re}$ & 36 & 1800 & 8.3 & 63 \\
\hline $238 \mathrm{U}$ & 0.0057 & 1.2 & 0.00028 & $0.002 ?$ \\
\hline
\end{tabular}

To ensure that the both intruder and groundwater limits are satisfied, several actions will be implemented to augment the current waste acceptance practice. Presenily, the generator is required by the WAC (WIC-EP-0063-4) to provide radionuclide specific inventory and concentrations per container. Additional actions inciude the following:

* A set of trigger concentrations will be identified in the WHC-EP-0063-4 that are provided in Table 2. The trigger concentrations are $0.1 \%$ of intruder imits for the appropriate waste category. If the generator is sending waste for disposal with radionuclide concentrations that exceed the trigger concentrations, an estimate of the total inventory of those radionuclides that will be sent for disposal must also be provided to Waste Acceptance Services prior to shipment of waste. 
9407538B R1

Attachment 1

Page 8 of 16

Table 2. List of Radionuclide Specific Trigger Concentrations $\left(\mathrm{Ci} / \mathrm{m}^{3}\right)$ for Category 1 and 3 Waste

\begin{tabular}{|c|c|c|c|c|c|}
\hline Radionuclide & Cat. 1 & Cat. 3 & Radionuclide & Cat. 1 & Cat. 3 \\
\hline${ }^{14} \mathrm{C}$ & $3.3 \times 10^{-5}$ & $2.5 \times 10^{-4}$ & ${ }^{36} \mathrm{Cl}$ & $2.3 \times 10^{-5}$ & $\begin{array}{l}1.8 \times \\
10^{-4}\end{array}$ \\
\hline${ }^{79} \mathrm{Se}$ & $8.5 \times 10^{-6}$ & $6.3 \times 10^{-5}$ & ${ }^{99} \mathrm{TC}$ & $5.3 \times 10^{-5}$ & $\begin{array}{l}4.0 \times x \\
10^{-2}\end{array}$ \\
\hline${ }^{129} \mathrm{I}$ & $2.3 \times 10^{-7}$ & $1.9 \times 10^{-6}$ & ${ }^{187} \mathrm{Re}$ & $8.3 \times 10^{-3}$ & $\begin{array}{l}6.3 \times \\
10^{-2} x\end{array}$ \\
\hline U & $2.8 \times 10^{-7}$ & $2.2 \times 10^{-6}$ & & & \\
\hline
\end{tabular}

* Upon receipt of this information, Waste Acceptance Services will evaluate the need for further action before accepting the waste. Three types of actions can be derived as a result of the evaluation process. First, the radionuclide inventories may be sufficiently small to accept the waste as is. Second, some waste treatment resulting in the development of a waste form may be required which increases the immobilization of the radionuclide inventory and therefore increases the allowable inventory that can be accepted for disposal. The primary waste form material is grout. Third, the waste may be rejected if the radionuclide inventory is too large and no adequate waste form can be developed. The appropriate action will be based on the PA results where inventory limits are quantified as a function of waste form performance (no performance, diffusion coefficients, or solubility control). The results of the evaluation will be transmitted to the generator and the appropriate actions will be implemented before waste is sent to the disposal facility.

* A tracking system will be developed which identifies the location of wastes containing these radionuclides. Curie limits will be established on a trench by trench basis and disposal of wastes containing these radionuclides will be monitored as new waste is disposed to ensure that the inventory limits are not exceeded. The Curie limits are easily calculated for the trenches because they are oriented parallel to the general direction of flow. Thus, the limits identified for $1 \mathrm{~m}$ of trench can be multiplied by the width (m) of the northsouth dimension of the trench to define the trench specific limit.

Based on the wastes received to date and the future waste projections, it is expected that few waste streams will require evaluation or further waste treatment prior to acceptance. Two waste stream types that have been and that are received would have to be evaluated per this procedure. They have been evaluated in this PA and do not require subsequent consideration. These are uranium metal or uranium oxide waste and activated metals containing large inventories of ${ }^{14} \mathrm{C}$ (primarily naval reactor waste). The uranium metai and uranium oxide wastes have typically been grouted using a Portland cement-based 
9407538B R1

Attachment 1

Page 9 of 16

material to eliminate their flammable characteristics. This type of grouting is also required to satisfy the PA requirements. The radionuclide inventory in the naval reactor waste is effectively immobilized in the activated metal matrix and encapsulated by additional metal or metal/cement containers. For these wastes, the estimated radionuclide release fluxes are minimal and potential dose from these sources are essentially negligible. Therefore, no additional waste form performance is required and the waste is acceptable for performance.

Comment 1.d: The classification criteria for category 1 and 3 wastes and the rationale for not defining a category 2 .

Response: Prior to the development of the PA derived classification system presented in this document, an initial categorization of waste was implemented that copied the NRC classification format. To distinguish between the Hanford classification scheme and the NRC system, the waste classes were labeled 1,2 and 3 and generally corresponded to Class $A, B$, and $C$. The classification scheme is intended to provide greater levels of protection and isolation going from $C l a s s$ A to Class $C$ or Category 1 to Category 3 . Consequently, larger inventories could be accepted in the more protected waste. The primary function of a Class B or 2 waste is to deter the intruder from coning in contact with the waste for some period of time beyond the minimum 100 years of institutional control. The NRC classification was conceptualized for moderate half life (up to $100 \mathrm{yr}$ ) radionuclides that would be significantly reduced in activity during the extended time prior to intrusion.

As the PA was developed, it was decided that the Category 2 waste class could be included in the Category 3 class categorization. This was done for two reasons. First, the Class 3 requirements are essentially equivalent to Class $C$ requirements and therefore more protective than Class B or Category 2 requirements. Second, actual disposal practice for any waste disposed that contains radionuclide concentrations greater than Category 1 imits will turn out to be equivalent to Category 3 requirements (i.e., stabilized waste and thick cover). This practice is expected because the present burial grounds must go through RCRA closure. RCRA closure includes a RCRA cap or equivalent that will be added on top of the $8 \mathrm{ft}$ of fill dirt that is currently applied to the top of the waste to limit radiation emissions into the atmosphere during operations.

Category 3 could have been labeled Category 2. However, it is useful to retain the connotation of equivalence with $\mathrm{C}$ ]ass $C$. Further, the nomenclature has been used for some time and a change at this juncture will create unnecessary confusion among generators and disposal facility operators.

Comment 1.e.: Copies of "Hanford Site Solid Waste Acceptance Criteria". WHC-EP$0063-4$.

Response: Copies of this document are provided in this attachment. 
9407538B R1

Attachment 1

Page 10 of 16

Comment 2.a.: Errata which details corrections, such as typographical errors in the PA; include the units for each parameter listed in each of the equations in the $P A$.

Response: A copy of an errata sheet is provided in the attachment.

Comment 2.b.: The units for values presented in Tables 4-5 and B-5; include a discussion of how the values in Table 4-5 were derived.

Response: The units of measure for Table 4-5 are "mrem/yr per $C j$ exhumed". The units of measure for Table B-5 are " $\mathrm{Cj} / \mathrm{m}^{3}$ ". The purpose of Table $4-5$ is to indicate the quantitative differences in radionuclide specific doses for the different exposure pathways that result from the mixing of waste with soil and subsequent growth and consumption of crops. The exposure pathways listed in Table 4-5 include external exposure to direct gamma, inhalation, soil ingestion, and crop consumption as well as total dose. Dose from crop consumption is split into two categories "Root Up" (root uptake) and "Rain Sp" (rain splash). These are the two primary means by which crops absorb radionuclides. By comparing the doses, one can determine which mechanism is dominant (usually root uptake).

The method of dose calculation for this table is the same as that for the post excavation and post drilling scenarios and the radionuclide specific total doses shown in Tables 4-3 and 4-4 are the sum of doses from all of the exposure pathways identified separately in Table 4-5. The specific dose values in Table 4-5 do not match the doses in Tables 4-3 or 4-4 because doses were calculated as a function each $\mathrm{Ci}$ of radionuclide removed from the disposal facility. In the intruder scenarios, doses are calculated as a function of the initial concentration of the radionuclide in the waste facility and different soil dilution factors. Ultimately, each assumption leads to a radionuclide concentration in the soil in which the plants are grown. The net effect of these slightly different approaches is an estimation of different soil radionuclide concentrations that are reflected in different total dose estimates.

Comment 2.c: Clarification of the apparent discrepancy between the Kd of 10 for neptunium listed in Table $3-5$ and the value of 1 that was used to derive the groundwater based 1 imit for neptunium in Chapter 4 .

Response: The discrepancy in the selection of the Kd value was an oversight. A site specific data base has been recently generated (Serne, et al 1993) indicating an average $\mathrm{Kd}$ value of $-20 \mathrm{~mL} / \mathrm{g}$. This contrasts to older sorption data collected using soils from other Eastern Washington locations. This data is the basis for assuming that a reasonably conservative $\mathrm{Kd}$ value for $\mathrm{Np}$ is 10 $\mathrm{mL} / \mathrm{g}$ and should be used to estimate transport through the soil column.

Comment 2.d.: Justification for not establishing a limit on ${ }^{241}$ Am derived from the groundwater-based $\mathrm{fimit}$ for ${ }^{237} \mathrm{~Np}$.

Response: Because both $\mathrm{Np}$ and Am are assumed to be characterized by Kd values $>10$, neither are predicted to reach the unconfined aquifer for tens of thousands 
of years. Consequently, no groundwater limit is considered reasonable for these radionuclides. The reference to a $\mathrm{Np} l i m i t$ in Table 4-25 will be deleted.

Comment 2.e: Explanation for the results presented in Table 4-18 which show a decrease in groundwater concentration when the source concentration is increased in contrast to the results presented in Table 4-19 which show a decrease in concentration when the source concentration is decreased.

Response: The PRP's observation is correct. The results on the highconcentration, in Figure 4-18 decreased from the base case peaks. This was due to the source location being place further from the well ( $X=110 \mathrm{~m}$ rather than at $X=100 \mathrm{~m})$. This occurred because the hot spot was placed in the middle of the trench rather than at the eastern edge of the trench.

Below are the new results for the high concentration source, with the source relocated at approximately $X=100 m$ away from the well for equivalent comparison with the base case.

\begin{tabular}{|c|c|c|c|c|c|}
\hline Run Number & $\begin{array}{c}\text { Recharge } \\
\text { rate } \\
(\mathrm{cm} / \mathrm{yr})\end{array}$ & $K d(\mathrm{~mL} / \mathrm{g})$ & $\begin{array}{c}\text { Inventory } \\
\text { depletion } \\
\text { period } \\
(\mathrm{yr})\end{array}$ & $\begin{array}{c}\text { Peak } \\
\text { concentrat } \\
\left.\text { ion (ci } / \mathrm{m}^{3}\right)\end{array}$ & $\begin{array}{c}\text { Time to } \\
\text { peak } \\
\text { concentrat } \\
\text { ion (yr) }\end{array}$ \\
\hline $\begin{array}{c}\text { base-case } \\
\text { (la) }\end{array}$ & 5.0 & 0 & 25 & $7.96 \times 10^{-5}$ & 123 \\
\hline $\begin{array}{c}\text { old hot } \\
\text { spot (4a) }\end{array}$ & 5.0 & 0 & 25 & $7.76 \times 10^{-5}$ & 127 \\
\hline $\begin{array}{c}\text { new hot } \\
\text { spot (4b) }\end{array}$ & 5.0 & 0 & 25 & $1.04 \times 10^{-5}$ & 995 \\
\hline $\begin{array}{c}\text { base-case } \\
(2 \mathrm{a})\end{array}$ & 0.5 & 0 & 25 & $1.01 \times 10^{-5}$ & 1030 \\
\hline $\begin{array}{c}\text { old hot } \\
\text { spot (4a-1) }\end{array}$ & 0.5 & 0 & 25 & $1.05 \times 10^{-5}$ & 985 \\
\hline $\begin{array}{c}\text { new hot } \\
\text { spot (4b-1) }\end{array}$ & 0.5 & $0.16 \times 10^{-5}$ & 121 \\
\hline
\end{tabular}

The results for $4 b$ and $4 b-1$ are consistent with the assumption that the higher concentration source should always increase the peak concentration slightly.

Comment 2.f: Justification for the neglect of erosion

Response: Two sources of information indicate that a cover can be designed to prevent erosion over a long period of time. First, observation of the natural environment indicates that there are 1 arge areas of the 200 Area Plateau that do 
HNF-SD-WM-TI-798, Rev. 0

$9407538 B$ R1

Attachment 1

Page 12 of 16

not undergo long term erosion. These areas are well vegetated with a mixture of shallow and deep-rooted plants typical of a shrub-steppe environment. There are no indications of consistent water erosion or wind erosion. Prior to construction of trenches, the 200 West Area LLBG were an example of this kind of area. Second, a fairly significant research program (the Hanford Barrier Program) has been in $\mathrm{place}$ to develop disposal facility or waste site covers that would survive over the long term. The primary functioning component is the top layer which consists of a vegetated soil containing a large fine grained component and a pea gravel component. The vegetation consists of a mixture of naturally occurring plants. These features have been developed to combat the potential for wind and water erosion.

The general hypothesis is that under normal vegetated conditions, gradual deposition of soil is likely to occur as the vegetation traps wind blow soil. on the other hand, periodic drought and wildfire events could temporarily kill vegetation thus exposing the surface and making it more vulnerable to erosional processes. Thus, episodic erosional events could occur. A series of small scale wind and water erosion experiments were conducted to measure erosion as a function of changes in soil and atmospheric parameters.

The wind erosion experiments are summarized in Ligotke (1993). Erosion data were derived from wind tunnel experiments. The various soil conditions studied were $100 \%$ soil, soil with a significant pea gravel component ( $30 \%$ ), and crusted soil. Crusted soil was created by exposing the soil to cycles of moisture and drying prior to experimentation. The soils were subjected to winds at variable speeds for different lengths of time. Wind speeds were selected to include the occasional large velocity gusts that have been measured at the Hanford site. Saltation effects were al so evaluated by suspending particulate matter in the wind. The primary observation was that the addition of pea grave? to soil was a very effective agent in reducing the erosion rates (by factors of 20 to 100). In addition, comparison of erosion from shorter versus longer term experiments shows that total erosion is essentially constant. This suggests that the pea gravel acts to armor the surface such that the erosion process is shortlived and finite. The formation of a soil crust was also shown to be effective in reducing erosion.

The water erosion experiments are summarized in Gi]more and Waters (1993). Erosion data were derived using rain simulators over field plots. Bare soil, soil gravel mixtures, and vegetated soils were all tested. The rain simulator was set up to provide high intensity precipitation for fairly short periods of time (from 20 to 60 minutes). These conditions compare with infrequent storms predicted to occur every $100 \mathrm{yr}$ for longer durations (up to a day). In all cases, runoff was created, although not before the soil was sufficiently moisturized. However, the loss of soil was minimal. The collected sediment quantities were be approximately translated into erosion depths, the maximum being $<5 \mathrm{~mm}$ under bare soil conditions with or without the gravel admixture. The presence of vegetation proved to be the most efficient means of minimizing water erosion. An interesting incidental observation is that the vegetation appeared 
$9407538 \mathrm{~B} \mathrm{Rl}$

Attachment 1

Page 13 of 16

on the test plots without any assistance from the experimentalists. Because of intermittent funding, the plots were left untended for 18 months and greater than $80 \%$ of the area was covered by cheatgrass and other species when testing was resumed.

In addition to these smaller scale tests, a prototype barrier has been constructed in the 200 East Area. Instrumentation has been provided to measure the degree of erosion on a larger scale. These data are expected to provide additional data to support the contention that minimal erosion may occur episodically with a properly designed cover and that periods of deposition will counterbalance the erosional effects.

Comment 2.g.: Justification for the neglect of upward contaminant migration by capillary action.

Response: The anticipated $10 \mathrm{w}$ recharge for the 200 West Area LLBG provides potential for upward migration of contaminants by capillary action. In particular, ground-surface evaporation may cause an upward capillary pressure gradient which is sufficient to overcome gravity and to move infiltrated water back toward the surface by a process called capillary rise. The delivery of water to the surface by this mechanism is also referred to as exfiltration (as opposed to infiltration). The one-dimensional, transient flow of water in an unsaturated medium can be written as:

$$
\frac{\partial \theta}{\partial t}=\frac{\partial}{\partial z}\left[D(\theta) \frac{\partial \theta}{\partial z}+K(\theta)\right]
$$

where $z$ is distance, $t$ is time, $\theta$ is volumetric moisture content, $k(\theta)$ is unsaturated hydraulic conductivity, and $D(\theta)$ is soil diffusivity:

$$
D(\theta)=K(\theta) \frac{\partial \psi}{\partial \theta}
$$

A considerable simplification of $\mathrm{Eq}$. (1) is possible (resulting in its transformation into an ordinary differential equation) by omitting the explicit effect of gravity, $\partial \mathrm{K} / \partial \mathrm{z}$. This term is negligible whenever the effect of gravity is small compared to that of capillarity (i.e., $\partial \psi / \partial z \gg 1)$. Such a condition can occur when the moisture content is relatively low. Omitting the gravitational term, Eq. (1) yields:

$$
\frac{\partial \theta}{\partial t}=\frac{\partial}{\partial z}\left[D(\theta) \frac{\partial \theta}{\partial z}\right]
$$


94075388 R1

Attachment 1

Page 14 of 16

Using the assumption of constant diffusivity, Eq. (3) can be made linear as:

$$
\frac{\partial \theta}{\partial t}=D \frac{\partial^{2} \theta}{\partial^{2} z}
$$

The solution of Eq. (4), subject to an initial moisture content of $\theta_{i}$ and exfiltration with a constant surface moisture content of $\theta_{0}\left(\theta_{i}>\theta_{0}\right)$ is (Eagleson, 1970):

$$
\frac{\theta-\theta_{0}}{\theta_{i}-\theta_{0}}=\operatorname{erf}\left[\frac{|z|}{2 \sqrt{D t}}\right]
$$

where erf is the error function.

Upward migration of contaminants by capillary rise is not a problem as long as the "penetration depth" obeys (Eagleson, 1970):

$$
4 \sqrt{(D t)} \ll Z
$$

Alternatively, for a soil cover thickness of $Z \mathrm{~m}$, the exfiltration duration, $T$, is given by:

$$
T \leq \frac{Z^{2}}{16 D}
$$

Natural Hanford sediments below the near-surface zone affected by seasonal, diurnal, and plant evapotranspiration cycles generally are found to have a moisture content between 4 to 7 percent by volume. Assuming a minimum soil cover thickness of $Z=3 \mathrm{~m}$ and a computed diffusivity $\mathrm{D}(\theta)$ (based on the moisture characteristic curves of Figure A-27 for Hanford formation) of $8.58 \times 10^{-8} \mathrm{~cm}^{2} / \mathrm{s}$ for an average volumetric moisture content of 5 percent, the time $T$ is estimated to be approximately 2,080 years. This suggests that, for any significant upward migration of contaminants to occur by capillary rise, the exfiltration period has to continue in excess of about 2,080 years. Such an extended dry period is considered highly un 7 ikely. The fact that precipitation occurs episodically, at times at much higher rates than the assumed average rate, and the soil cover is subject to infiltration-redistribution cycles, upward radionuclide migration by capillary rise is not considered a viable means of providing any significant dose.

Reference

Eagleson, P. S., 1970, Dynamic Hydrology. McGraw Hill, N.Y., 462p. 
$9407538 B$ R1

Attachment 1

Page 15 of 16

Comment 2.h.: Justification for the assumption of one-dimensional, semi-infinite slab geometry for the diffusion-controlled case; discuss the degree to which this assumption is conservative or non-conservative.

Response: The assumption of a semi-infinite slab release model produces essentialiy the same results as a finite slab model. In the diffusion model the release rate is inversely proportional to the square root of time. This means that the bulk of the release occurs early on, followed by a drop to zero. The semi-infinite slab model differs from the finite slab model primarily in that the resulting release rate approaches zero asymptotically. This results in a long, low tail of flux that is not present with the finite model. This tail contributes very little to the peak concentration in the drinking well and, in fact, is truncated for the VAM $3 D C G$ model. Because we are only concerned with peak groundwater concentrations and peak doses, the slab geometry is inconsequential.

Comment 2.i.: Description of the point of exposure in the calculation of atmospheric dose.

Response: The calculated dose is estimated essentially at the edge of the waste. The model assumes that the point of exposure is the boundary of the waste site. since the waste site (the emission source) was assumed to be a square with an area of one hectare, the inhalation dose at the waste site boundary will be very similar to the inhalation dose at the center of the waste site.

Comment 2.j.: Resolution of the apprirent discrepancy between the forecasted waste volumes presented on pages $2-20$ and $2-23$.

Response: A more up to date volume projection has been published since the estimates used in the final PA valero, et al, 1994). The new numbers will ultimately be incorporated in the revised PA. Although the numbers provided below are different the relative proportions remain similar.

\begin{tabular}{|l|l|l|l|}
\hline $\begin{array}{l}\text { Generator } \\
\text { Defense Waste } \\
\text { Management }\end{array}$ & LLW & LLMW & Total \\
\hline $\begin{array}{l}\text { Chemical } \\
\text { Processing } \\
\text { Other Onsite } \\
\text { Facilities }\end{array}$ & 32,100 & 129,900 & 239,400 \\
\hline $\begin{array}{l}\text { Offsite } \\
\text { Facilities }\end{array}$ & 172,800 & 10,100 & 42,300 \\
\hline
\end{tabular}

With regard to the primary offsite generators, they are Oak Ridge Nationat Laboratory, also referred to as FUSRAP $\left(57,500 \mathrm{~m}^{3}\right)$, Paducah $\left(52,700 \mathrm{~m}^{3}\right)$, Portsmouth $\left(29,800 \mathrm{~m}^{3}\right)$, Brookhaven National Laboratory $\left(14,200 \mathrm{~m}^{3}\right)$, Argonne 
HNF-SD-WM-TI-798, Rev. 0

9407538B R1

Attachment 1

Page 16 of 16

National Laboratory $\left(12,000 \mathrm{~m}^{3}\right)$, Lawrence Berkeley Laboratory $\left(10,700 \mathrm{~m}^{3}\right)$, Lawrence Livermore National Laboratiory $\left(6900 \mathrm{~m}^{3}\right)$, and the Princeton Plasma Physics Laboratory $\left(6,000 \mathrm{~m}^{3}\right)$. The other offsite facilities combined are predicted to provide $12,600 \mathrm{~m}^{3}$ of waste.

Comment 2.k.: Comparison of the calculated uranium groundwater concentrations with the Proposed Maximum Concentration Leve 1 of $20 \mu \mathrm{g} / \mathrm{L}$.

Response: The base case analyses assuming solubility control of release show initial concentration to peak concentration ratios of $7.6 \times 10^{-3}$ and $8.3 \times 10^{-4}$ for Category 1 and Category 3 facility conditions (Table $D-6$ ). Assuming the uranium solubility values for soil and port 7 and cement $\left(6.4 \times 10^{4}\right.$ and $2.4 \times 10^{2}$ $\mu \mathrm{g} / \mathrm{L}$, respectively) are the initial concentrations, the peak groundwater concentrations can be calculated by ratio. Assuming Category l conditions, peak groundwater concentrations for the soil and cement-controlled chemical environment are 484 and $1.8 \mu \mathrm{g} / \mathrm{L}$. Assuming Category 3 conditions, peak groundwater concentrations for the soil and cement-controlled chemical environment are 53 and $0.2 \mu \mathrm{g} / \mathrm{L}$. Thus, the cement controlled solubility is sufficient to satisfy the uranium MCL, but the soil solubility is not. 
Errata for the SWPA (November 1994 version)

General Chantes:

Change ail references in the texs of the DOE-RL 5820.2A supplement to RLID $5820.2 \mathrm{~A}$ to (DOE, 1993a)

Plan view mans of the 200 West Area LLBG will be revised to include the undeveloped burial ground land (expansion area) that is atjacent to and west of the current burial grounds - -

Specitic Changes:

D. xii. Table $\mathrm{S}-2$. (hange $20 \mathrm{pCi} \mathrm{m}^{2} / \mathrm{s}^{\prime} \mathrm{t}$ " $20 \mathrm{pCi} / \mathrm{m}^{2} \mathrm{~s}(\leq 10.000 \mathrm{yr})$. Change atmospheric dispersion Caterory I vilue w "0.012" and the atmospheric dispersion Category 3 value to N/A.

D. xii. 3rd and 4h semt. End the third sentence after "uranium". Start the 4th sentence "With the exception..."

D. xii, 5th sent. Delete "With the exception of ${ }^{222} \mathrm{Rn}$ "

2. xii. Delete the last two sentences.

D.xv. Change "Liquid Efthuent Treatment Favility" to "Liquid Etfluent Retention Facility".

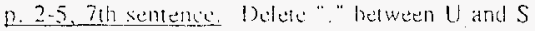

D. 2-13,2-14. Show LLBG explansion atrea on the map.

D. 2-20, Table 2-1. Replate numbers in table with numbers provided helow. Change source document (1) Valero, et ill. (1904) in the tihle and every where else in the document.

\begin{tabular}{|c|c|c|c|}
\hline Generatur & LIE & LLMW & Total \\
\hline $\begin{array}{l}\text { Defense Wiste } \\
\text { Managenent }\end{array}$ & 109.500 & 129,900 & 239.400 \\
\hline Chemicat Processing & .32 .100 & 10.100 & 42.300 \\
\hline Other Onsile Fancilities & 44.500 & 900 & 45.400 \\
\hline Otfsite Filcilities & 172.800 & 29.600 & 202.400 \\
\hline
\end{tabular}


HNF-SD-WM-TI-798, Rev. 0

$9407538 B$ R1

Attachment 2

Page 2 of 7

p. 2-21, line 3. Change "Treatment" to "Retention"

p. 2-21, lst para. Change "the grout facility" to "further use of the grout facility"

p. 2-22, Section 2.3.3. Change "Kaiser Engineers Hanford" to "ICF Kaiser".

p. 2-23. Section 2.3.4, 1st para. Change "Fermi Laboratory" to "Fermi Nationai Accelerator Laboratory". Change "Battelle Columbus Operations" to "Battelle Columbus Laboratories". Change "Stanford University" to "Stanford Linear Accelerator center".

E. 2-23. Section 2.3.4, 2nd para. Replace the fourth paragraph with the following:

The volume forecast projections indicate that the largest contributors of wasste will be Oak Ridge National Laboratory, also referred to as FUSRAP $\left(57,500 \mathrm{~m}^{3}\right)$, Paducah $\left(52,700 \mathrm{~m}^{3}\right)$, Portsmouth $\left(29,800 \mathrm{~m}^{3}\right)$, Brookhaven National Laboratory $\left(14,200 \mathrm{~m}^{3}\right)$, Argonne National Laboratory $\left(12,000 \mathrm{~m}^{3}\right)$, Lawrence Berkeley Laboratory $\left(10,700 \mathrm{~m}^{3}\right)$, Lawrence Livermore National Laboratory $\left(6900 \mathrm{~m}^{3}\right)$, and the Princeton Plasma Physics Laboratory $\left(6,000 \mathrm{~m}^{3}\right)$. The other offsite facilities combined are predicted to provide $12,600 \mathrm{~m}^{3}$ of waste during the $30-y \mathrm{r}$ period. These estimates include LLMW as well as LLW to be disposed at the LLBG.

p. 2-23. Last sent. Insert "usual7y" after "are".

D. 2-27. Show LLBG expansion area on the map.

D. 3-4, Eq. 2. Change unit of measure for " $M$ " in Equation 2 to " $\mathrm{kg} / \mathrm{m}^{3}$ ".

p. 3-9, Table 3-3. Under column 2-.. Switch "Steady-state velocity field" from the 2nd row with "Infiltration rate" from the 3rd row.

p. 3-15, Ist sentence following eq. (3.12). Insert "the" after "containers are". p. 3-15. 2nd sentence following eq. (3.12). Add the unit of measure "per m" after 5.33. 
$9407538 B$ R1

Attachment 2

Page 3 of 7

p. 3-25, Table 3-4. Replace with the following table.

\begin{tabular}{|c|c|c|c|c|c|c|c|c|c|}
\hline Sample & $\begin{array}{l}\text { Formation } \\
\text { Type }\end{array}$ & $\begin{array}{l}\text { Materi } \\
\text { al }\end{array}$ & $\begin{array}{l}\text { Depth } \\
\text { (m) }\end{array}$ & $\theta$ & $\theta_{\mathrm{r}}$ & $a(1 / m)$ & $n$ & $\begin{array}{c}K_{s} \\
(m / y r)\end{array}$ & )$^{\left(\mathrm{g} / \mathrm{cm}^{\rho_{\mathrm{t}}}\right.}$ \\
\hline 0.069 & Hanford & (1) & 3.05 & 0.301 & 0.000 & 9.45 & 1.2515 & $\begin{array}{l}6,496 . \\
4\end{array}$ & 2.29 \\
\hline $0-072$ & E.P. & (2) & 19.82 & 0.391 & 0.056 & 0.90 & 2.0877 & 517.12 & 1.81 \\
\hline 0.082 & Plio & (3) & 24.70 & 0.455 & 0.127 & 4.86 & 1.3520 & $2^{1,892 .}$. & 9.43 \\
\hline $0-107$ & U.R. & (4) & 40.40 & 0.317 & 0.025 & 9.16 & 1.807 & $5,203$. & 1.59 \\
\hline $0-107$ & M.R. & (5) & 40.40 & 0.317 & 0.025 & 9.16 & 1.807 & $\frac{5,203 .}{4}$ & 1.59 \\
\hline
\end{tabular}

p. 3-14, 2nd para. Replace "diffusion with "diffusive".

p. 3-14, 3rd para. 2nd line before eq. (3.10). Change $Q$ to $Q(C i / y r)$.

p. 3-21. Fiqure3-1. Replace with the new Finite Element Mesh figure.

p. 3-24. para. 4. line 7. Change "date" to "data".

D.3-27, Section 3.2.3.3.4., line 6. Change "kd" to "Kd".

p. 4-8, Table 4-5. Replace title with the following: "Comparison of Dose (mrem/yr per $\mathrm{Ci}$ exhumed) to the Intruder by Exposure Pathway at 300 Years Postclosure"

p. 4-13, Section 4.1.3.2, lst para. Change "4.2.3.1" to "4.1.3.1".

p. 4-20, Figure 4-2. Replace with new velocity plot for $5 \mathrm{~cm} / \mathrm{yr}$ with the reference arrow 1 abeled $0.05 \mathrm{~m} / \mathrm{yr}$.

p. 4-24, Figure 4-6. Replace with new velocity plot for $0.5 \mathrm{~cm} / \mathrm{yr}$ with the reference arrow labeled $0.005 \mathrm{~m} / \mathrm{yr}$.

p. 4-42, Table 4-17. Last column, 2nd row--- Replace 1,000 with 100.

p. 4-43, Table 4-18. Last column, last row--- Replace 103 with 1030.

p. 4-59, 3rd para. ...K( $(\theta)$ versus $\theta$ not $K(q)$ versus $q$.

p. 4-60, last para. 2nd line. Change particle to pore.

p. 4-61, bulletized items. Delete "." between U and $S$ in US Ecology 
D. 4-61, last para. Delete "." between $U$ and $S$ in US Ecology.

D. 4-61, 4th line from bottom. Change form to from.

p.4-62. Show LIBG expansion area on the map.

p. 4-66, Table 4-24. Change ${ }^{36} \mathrm{Cl}$ Category 1 1 imit to $6.4 \mathrm{E}-04$.

p. 4-71. Table 4-25. Replace the NA descriptor for unranium under Category 3 columns with $2.1 \mathrm{E}-03$ in the

"I m trench" subcolumn and 3.7 in the "Whole Facility" subcolumn. Delete the Np237 row.

p. 5-1. Table 5-1. Change radon emission Category I value to "0.0012". Change atmospheric dispersion Category 1 value to "0.012" and the atmospheric dispersion Category 3 value to NA.

D. 7-2. Replace the reference DOE-RLID with "DOE, 1993a, RLID-5820.2A, Radioactive Waste Management, Richland Operations Implementation Directive (RLID) to DOE Order 5820.2A."

p. A-11. Show LLBG expansion area on the map.

D. B-31 Table B-5. Add the units of measure $\left(\mathrm{Ci} / \mathrm{m}^{3}\right)$

E. $\mathrm{C}-32$ through $\mathrm{C}-35$. Delete Tables $\mathrm{C}-12$ and $\mathrm{C}-13$.

D. D-6, Figure D-3. Change $0.1 \mathrm{~m} / \mathrm{yr}$ reference arrow to $0.05 \mathrm{~m} / \mathrm{yr}$.

p. D-8. Figure D-5. Change $0.01 \mathrm{~m} / \mathrm{yr}$ reference arrow to $0.005 \mathrm{~m} / \mathrm{yr}$.

D. Gl-17.

$\sigma_{\beta}^{2}=v a r i a n c e$ of the slope of the In $K$ vs. $\psi(K, \mathrm{~m} / \mathrm{s} ; \psi, \mathrm{m}) \ldots$

$\mathrm{H}=$ mean value of $\psi(\mathrm{m})$

$\lambda$ =correlation length (m) for both $7 n K_{s}$ and $\beta$ random...

$\mathrm{A}=$ mean slope $\left(\mathrm{m}^{-1}\right)$ of $7 \mathrm{n} \mathrm{K}$ vs. $\psi$

p. G2-7 eq. $(G 2-2,1)$.

$\rho_{\mathrm{H}}=$ density of water $\left(\mathrm{kg} / \mathrm{m}^{3}\right)$

$\Psi=$ pressure head $(\mathrm{m})$

$K_{i j}=$ saturated hydraulic conductivity tensor ( $\mathrm{m} / \mathrm{yr}$ )

$x_{i}=(j=1,2,3)$ a set of orthognal spatial coordinates (m)

$\mathrm{t}=\mathrm{t}$ ime $(\mathrm{yr})$

$q=$ volumetric flow rate... $\left(\mathrm{m}^{3} / \mathrm{yr} / \mathrm{m}^{3}\right)$ 
9407538B Rl

Attachment 2

Page 5 of 7

p. G2-8 eq. $(G 2-2.7)$.

$D_{i j}=$ hydrodynamic dispersion tensor $\left(\mathrm{m}^{2} / \mathrm{yr}^{\mathrm{r}}\right)_{3}$

$\mathrm{c}=$ solute concentration in the fluid $\left(\mathrm{Ci} / \mathrm{m}^{3}\right)$

$v_{i}=$ Darcy velocity $(\mathrm{m} / \mathrm{yr})$

$\rho_{s}=$ density of solid grains $\left(\mathrm{g} / \mathrm{cm}^{3}\right)$

$\mathrm{c}_{\mathrm{s}}=$ mass of solute sorbed per dry unit weight of solid $(\mu \mathrm{Ci} / \mathrm{g})$

$\lambda=$ first-order decay coefficient (1/yr)

$c^{*}=$ solute concentration in the injected fluid $\left(\mathrm{Ci} / \mathrm{m}^{3}\right)$

p. G2-9 eq.(G2-2.9). Replace the phrase "with........ (1- $\phi) \rho_{\mathrm{s}}$." with "with the distribution coefficient $k d(\mathrm{ml} / \mathrm{g})$ and the bulk density, $\rho_{\mathrm{B}}$, being defined as (1ф) $\rho_{\mathrm{s}}$."

p. G2-10, eq. $(G 2-3 \cdot 1)$. Delete "the" from the phase "by the VAM3D-CG version $2.4 b$ on the SGI"

p. G2-38. Tab]e G2-8. Change unit $(m)$ to $(m / y r)$ under Hyd Cond (5th column).

D. G2-38, Table G2-9. Change "Total Hyd $K$ " to "Unsat. Hyd $K "$ (3rd column).

p. G2-41, 2nd para. Delete "the" from the phrase "for the comparison..."

p. G2-41, last para. Delete "the" from the phrase "in the each material"

D. G2-46, Fiqure G2-18. Change the title to "Material Types for the Finite element Geometry"

D. H-3, last 1 ine. Change "216-W-3AE" to "218-W-3AF".

p. H-4, item 2. Change "216-W-3AE" to "218-W-3AE".

p. H-4, item 3. List ERDF as the 618-12 burial ground.

p. H-5, 2nd para. Delete ". between $U$ and $S$ in US Ecology.

p. $\mathrm{H}-10$, last response. Change "216-W-4C" to "218-W-4C".

Missing Units:

p. 3-12, eq. $(3.5)$.

$v=$ vertical Darcy Velocity (m/yr)

$A=$ horizontal (planar) area of the disposal unit $\left(m^{2}\right)$

$L=$ vertical depth of the disposal unit (m)

p. $3-13$ eq. $(3.6)$.

$m=$ total facility inventory .... (Ci)

$V=$ total volume of the disposal unit. $\left(\mathrm{m}^{3}\right)$ 
p. $3-13$ eq. $(3.7)$.

$D_{e}=e$ ffective diffusion..... $\left(\mathrm{m}^{2} / \mathrm{yr}\right)$

$\mathrm{t}=$ time $(y r)$

p. $3-14$ eq. $(3.9)$.

$A=$ effective surface area.... $\left(\mathrm{m}^{2}\right)$

$\mathrm{C}_{0}=$ concentration in the container. $\left(\mathrm{C} i / \mathrm{m}^{3}\right)$

p, 3-14 eq. (3.10).

$A_{i}=$ the surface area of $i-t h$ container. $\left(\mathrm{m}^{2}\right)$

$A_{t}=$ total surface area of a 11 containers. $\left(\mathrm{m}^{2}\right)$

p. $3-15$ eq. $(3.11)$.

$\mathrm{I}=$ total inventory $(\mathrm{C} \mathrm{i})$

$V_{i}=$ the volume of $i$-th container. $\left(\mathrm{m}^{3}\right)$

$V_{t}=$ total volume of all containers. $\left(\mathrm{m}^{3}\right)$

p. 3-19 eg. $(3.13)$.

$\rho_{w}=$ density of water $\left(\mathrm{kg} / \mathrm{m}^{3}\right)$

$\Psi=$ pressure head $(m)$

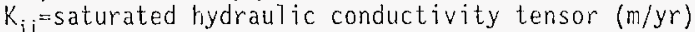

$x_{i}=(j=1,2,3)$ a set of orthognal spatial coordinates (m)

$\mathrm{t}=\mathrm{t}$ ime $(\mathrm{yr})$

$q=$ volumetric flow rate.... $\left(\mathrm{m}^{3} / \mathrm{yr} / \mathrm{m}^{3}\right)$

p. $3-20$ eq. $(3.15)$.

$\mathrm{g}=$ the gravitational constant (m/yr $\left.\mathrm{y}^{2}\right)$

$\alpha$ and $\beta=$ coefficients of compressibity $\left(\mathrm{m}^{2} / \mathrm{N}\right)$

p. $3-22$ eq. (3.18).

$\Psi_{a}=$ the air entry pressure head $(m)$

p. 3-22 eq. (3.19).

$D_{i j}=$ hydrodynamic dispersion tensor $\left(\mathrm{m}^{2} / \mathrm{yr}\right)$

$\mathrm{C}=$ solute concentration in the fluid $\left(\mathrm{C} i / \mathrm{m}^{3}\right)$

$v_{i}=$ Darcy velocity $(\mathrm{m} / \mathrm{yr})$

$\rho_{\mathrm{s}}=$ density of solid grains $\left(\mathrm{g} / \mathrm{cm}^{3}\right)$

$c_{s}=$ mass of solute sorbed per dry unit weight of solid $(\mu \mathrm{Ci} / g)$

$\lambda=$ first-order decay coefficient (1/yr)

$c^{*}=$ solute concentration in the injected fluid $\left(\mathrm{Ci} / \mathrm{m}^{3}\right)$

I $\mathbf{V} \mathbf{T}=$ absolute value of velocity $(\mathrm{m} / \mathrm{yr})$

p. 3-23 eq. (3.21). Add unit after $\mathrm{Kd}(\mathrm{ml} / \mathrm{g})$

p. $3-23$ eq. $(3.22)$.

$\alpha_{1}$ and $\alpha_{\mathrm{T}}=$ longitudinal \& transverse dispersivities (m)

$0^{6}=$ the bulk molecular diffusion coefficient $\left(\mathrm{m}^{2} / \mathrm{yr}\right)$ 
9407538B R1

Attachment 2

Page 7 of 7

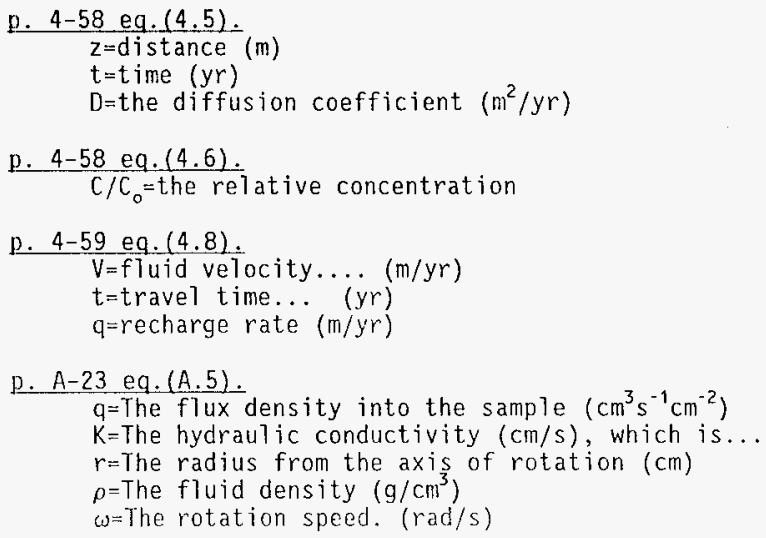

Conca, J.L. and J. Wright, 1990, Diffusion coefficients in gravel under unsaturated conditions, Water Resource Res., v. 26, pp. 1055-1066.

Valero, 0.J., K.J. Templeton, and J.L. Clary, 1994, 1994 Solid Waste Forecast Container Volume Summary, WHC-EP-0803. 


\author{
OATE: FEB 151995 \\ $R E B-Y$ TO \\ ATन OF: WPD:AKC 95-5WT-112
}

SUAJET: ADOITIONAL INFORMATION SUBMITTED TO PEER REVIEH PANEL ON 2OO WEST BURIAL GROUND PERFORMANCE ASSESSMENT, SUPPLEMENT 2

70: 3. A. Turi, Director

office of Program Integration, EM-33

Reference: EMail Message, E. L. Wilhite, WSRC, to M. I. Hood, WHC, "PRP Request for Information," dated February 2, 1995.

The referenced message requested additional information on the 200 West 8urial Ground Performance Assessmont. To expedita the process, this information has been sent via fax to nembers of the Pear Review Panel. In addition, any comments that EM-30 or other HQ organizations have on the subject document would be appreciated. Please address any zuestions that you may have on this subject to A. K. Crowell, of my stafi, on (509) $372-2346$.

Attachrnent

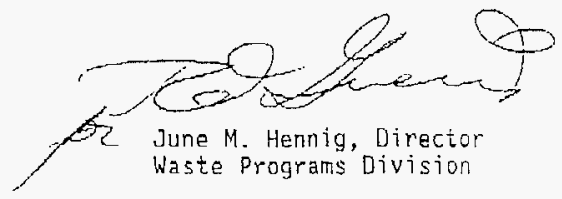

CC W/attach:

R. U. Cur?, EG\&G

G. J. Duggan, EM-332

w. R. Hansen, LANL

D. W. Layton, LLNL

E. L. Withite, WSRS

D. H. LeE, ORNL

R. Martinez, EM-363

S. M. Neuder, Battelle

R. 1. Nitschke, EG\&G Idaho

K. H. OWEnS, SAIC

G. J. Shott, REECo 
Comment 1: Provide additional discussion of (1) WAC develonment and implementation plans for incorporating PA requirements, inte waste disposal pracjices, and (2) the data management systom thit will keen track of waste inventory.

Response: Implementation of PA requirements in ILW disposal practices at Hanford is accomplished by locumenting the requirements in the waste aceeptance criteria document, Hanford Site Solid Waste Acceptance Criteria (WHC-EP-0063-4). As described below, some additional documentation is required. Within the Solid Waste Division of Westinghouse Fanford Company, Generator and Waste Acceptance Services (GWAS) and Solid Waste Management (SWM) are responsible for acesprance, and receipt and disposal of LLW, respectively. The first group is primarily responsible for ensuring the aceptability of waste to be disposed and the second group is responsible for disposal of the wasie. In addition, the Data Acquisition/Management Group is tesponsible for maintaining butial grounbl reands on a computer daca basi system, SWITS (Solid Waste Information Tracking System). For example, the data base information in Appendix B of the 200 West Area Butial Ground PA document was taker from SWITS. The following discussion is provided into two parts. First, a status of PA requirements already implemented in the waste management system; and second, a discussion of additional tasks to be completed to tully impiement the PA requirements are provided.

\section{Stasus}

The PA waste acceptance criteria address (1) protection of the intruter, and (2) protection of the groundwater and offsite individual. Currently, intruder protection requirements are present in the WAC (Table 3-1 in WHC-EP-0063 4 ). The primary criteria are radionuclide specific concentrations $\left(\mathrm{Ci} / \mathrm{m}^{3}\right.$ ) for two categories of waste, Carcgory 1 and Category 3. The generator is required to provide the radionuclicie specific activity and concontration for each container that is shipperl to the LLBG. Using a sum of fractions for waste containing multiple radionuclides, the waste classification can then be derermined for each container. Once the waste is accepted for disposal, the contuiner is disposed in the buriat ground. The trench in which the container is placed and its location in the ealst-west direction is entered into the burial ground record. The information on the burial ground recort is also recorded in SWITS. It is therefore nossible so determine the cumulative inventory present is a crench.

\section{Addicional Tisis}

To adequately address the PA requirements to protect groundwater and the ofisite individual, it is necessary to identity those wastes that could potentially provide unacceptable dose. The resulis of the 
PA unalysis show that a small number sf radionuclides are capable of providing significant groundwater concamination. Examination of the disposed wastes since the finalization of DOE Order $5820.2 \mathrm{~A}$ and projected waste indicated that only a sma!l number of waste streams contuin the particular zadionuclides nf concers at high enough activity leyels to be of concern. The radionuclides are long-lived and mobile in the Hanford soil-water environruen. Of these, uranium isotopes, ${ }^{99} \mathrm{Ic},{ }^{14} \mathrm{C}$, and ${ }^{129} \mathrm{I}$ are the most commonly listed. Because the acceptance limits are not concentrations bur colal inventory or solubility values, the cadionuclide concentration information currenty provided by the generatur must be augmented for the waste streams of concen to ensure that groundwater limits are not exceeded. The tcllowing actions will be taken to implement the PA groundwater protection requirements:

(1) Estabish trigger concentration limits for the groundwater mobile radionuclicles. The method of calculating trigger limits has been discussed in the previous response to the PRP's irtormation tequests. Place the trigger limits in the WHC-EP-0063 and require the generaror to provide an astimate of the inventory of these ractionuclioges for the total waşte stream planned for disposal at the LLBG if the trigger concentration limit is pxceeded. If more than one of the radiotuclides of concern is present in the waste, a sum of fractions calculation must be done to see if the combined total excesds the rigger concencration limits.

(2) Prepare a guidance sowment to GWAS thac defines the appropriate waste form and acceptable waste form characteristics for paricular radionudides. Given the uncertainties of waste stream projections, not all contingencies can be plarned for. However, the guidance document can provide waste form requirements that should apply to most of the wastes under consideration. These include a requirment to grout uranium waste, and another requizement that ties diffusion coetricient requirements to invenory activity in excess of the invencory acceptable without waste form perfomance. If diffusion chefficients are the required waste form characteristics, then a standard lenching procedure (e.g., ANS-16.1) will be required to show adequate performance betore the waste lan be accepted. If, in tack, a waste stream cannol be accoped using the requiremencs defined in the guidancs document, then the waste wiil be rejected or a supplementary PA analysis will be completed to evaluate alternate methods of treating and disposing the waste. 
(3) Estabiish a review process in GWAS to determine the acceptability of the waste to be received. Detcrmine whecher the waste cun be received as is, requires waste form performance, or cannot be accepted fur disposal. Based on the present information, it is likely that relatively few waste streams accepted by the LLBG will reguire waste form periomance. If necessary, the generator will he infomed of tulditional requirements that must be sarisited belore the witte can be accepted.

(4) Idencify inventory limits for each trench based on no waste form performance. Telentify those trenches that lie on line with eacin nther but exist in different burial grounis. Curtently, this situation occurs oniy for the northern buriai grounds (i.e., the 218-W-5, 218-W-3A, and 218-W-3AE) in the 200 West Area.

(5) Establish a routine computer rollup of inventory using SwITS for * trench that can be scanned prior io emplucing further waste containing groundwater mobile zadionuclides. It is conceivable that waste might bave to be stored temporarily if the guota has been reached at one trench and another one is not available to recive the waste. Huwever, there is usually more than one trench ayailable anci the wastes containing near limit inventories of the groundwater mobile radionuclides are rare. Consequently, disposal of such wasles will occur intermineatly. In addition, the identification of such wates by the GWAS should provicie sulficient lead time to plan the disposal.

(6) Revise operations procedures to require recurding of coordinates (within $10 \mathrm{~m}$ ) of the disposed waste containers in the north south direction for trenches with north-south widths grealer thar $20 \mathrm{~m}$ (e.s., the mixed waste trenches are $-100 \mathrm{~m}$ wide and would be tracked in $20 \mathrm{~m}$ wide increments).

Note: Prior to implementing any PA maintenance activiries, i short plan describing the process/steps will he forwarded to RL for information and comment.

Comment 2: Provide a reference to the equations uses in the comparison if dirfusion release estimates assuming a semi-infinice versus a finite slab genmetry.

Response: The reference is Crank (1975) which is listed in Chapter 7 of the 200 West Arce PA document. 


\section{APR 111995}

WPO:AKC 9S-SWT-232

SUEJECI: ADDITIONAL INFORHATION SUBMITTEO TO THE PEER REVIEH PANEL (PRP) ON THE 2OO WEST BURIAL GROUHD PERFORYANCE ASSESSMENT, SUPPLEHENT 3

10: \. A. Turi, Oirector

office of Program Integraxion, EM-33

Reference: Letter, Elmer L. Hilhite, PRP Chairman, to

J. M. Hennig, RL, "Third Request for Information on the Hanford 200-W-PA," SRT-WED95-0061, dated February 27, 1995.

In the referenced letter, the PRP requested additional information on the 200 West Burial Ground Performance Assessment. In order to provide the PRP an opportunity to review the information prior to their Aprit 18 \& 19 meeting, this information has been faxed to them. In addition, any coments that EM-30 or other Ha organizations have on the subject document would be appreciaced. Please address any questions that you may have on this subject to A. K. Crowell, of my staff, on (509) $372-2346$.

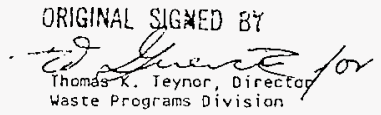

Attachment

CC whatach:

R. U. Curl, Lockheed Idaho

G. J. Duggan, EH-332

W. R. Hansen, LANL

D. W. Layron, LLNL

E. L. Wilhite, WSRC

o. H. Lee, ORNL

R. Martinez, EH-363

S. H. Neuder, Battelle

R. L. Nitschke, Lockheed Idaho

K. W. OWens, SAIC/HO

c. J. Shott, REECo

bCC: SHT RDG FILE

SHT OFF FILE (H/ATTACH)

WPD ROG FILE

AHIH ROG FILE

CCC OFF FILE (H/ATTACH)

AK CrOWELI, (W/ATTACH AND BACKGROUNO)

file U: lipdatal95\$ST 232

Record Hote: DOE Order 5820.2A requires that active and future disposal facilities have Performance Assessments (PA) to evaluate the long term performance. The Peer Review Panel (PRP) is a EM-30 panel chartered to evaluate the technica! adequacy and completeness of PAs. In November 1994, the PRP accepted the 200 West Performance Assessment for final revieH. Subsequent to their acceptance, the PRP has made three requests for additional information. This memorandum transmits the additional

information (third request) to HO. The PRP is meeting in Livermore, CA on April 18 \& 19 to discuss this information. The author of the PA will participate. The Chairman of the PRP specified chat this should be the last request. According to the $1 \mathrm{mplementation} \mathrm{Plan} \mathrm{for} \mathrm{DNFSB} 94-2$, this document is scheduled fo be approved by EM-30 in August 1995. 
HNF-SD-WM-TI-798, Rev. 0

Response to PRP comments from February 22-23 meeting:

1. Elimination of Highly Sorbing Radionuclides.

In the PA, radionuclides were categorized into groups with similar sorptive characteristics to reduce the number of analyses (Table 3-5 in Chapter 3). The group $\mathrm{Kd}$ values were $0,1,10$, or 100 depending on the known behavior of the radioisotopes. In all cases, conservatively low Kd values were chosen to increase estimated travel times and peak concentrations in the unconfined aquifer. For some radionuclides, extremely conservative $\mathrm{Kd}$ values were selected when the contribution to dose was expected to be very slight even with the use of the ultraconservative Kd value, as reflected in the values shown in the PA (Table 3-5).

Assumption of extremely conservative Kd values for short half live radionuclides was used as a screening device to eliminate these radionuclides from further consideration in the groundwater contamination scenarios. Two examples of this approach are ${ }^{137} \mathrm{Cs}$ and ${ }^{00} \mathrm{Sr}$ whose half lives are each about $30 \mathrm{yr}$. Even assuming a $\mathrm{Kd}$ of $1 \mathrm{ml} / \mathrm{g}$, essentially complete decay occurs before these isotopes reach the unconfined aquifer. More reasonably conservative $K d$ values are 100 and $10 \mathrm{ml} / \mathrm{g}$. Serne, et al (1993) measured $\mathrm{Kd}$ values of $>500 \mathrm{ml} / \mathrm{g}$ for ${ }^{137} \mathrm{Cs}$ and $>10$ to $20 \mathrm{ml} / \mathrm{g}$ for ${ }^{\text {10 }} \mathrm{Sr}$, respectively, in soils near and in the 200 West Burial Grounds. In the PA, an argument was provided that radionuclides with $\mathrm{Kd}$ values of $>100 \mathrm{ml} / \mathrm{g}$ do not require inventory limits to protect groundwater because the travel times to the unconfined aquifer are well beyond the performance goal of 10,000 yr. Given that a reasonable estimate of the $\mathrm{Kd}$ for $\mathrm{Cs}$ exceeds $100 \mathrm{ml} / \mathrm{g}$, a groundwater protection limit is also not required for the long-lived isotope, ${ }^{135} \mathrm{Cs}$.

A Kd value of 10 was assumed in the PA analysis for ${ }^{107} \mathrm{Pd}$ and ${ }^{226} \mathrm{Ra}$. These values were used because the combination of the low inventory of these radionuclides 10 activity was reported for ${ }^{107} \mathrm{Pd}$ in the inventory listed in Appendix $B$ ) in the disposed waste and the very conservative $\mathrm{Kd}$ value resulted in an estimate of an insignificant contribution to dose by groundwater contamination. Measurements of ${ }^{226} \mathrm{Ra} \mathrm{Kd}$ values of $>100 \mathrm{ml} / \mathrm{g}$ are reported by Ames and Rai (1978) on soils and water chemistry very similar to the Hanford Site (e.g., sandy soils, moderately alkaline $\mathrm{pH}[-8]$, and moderate total dissolved solids). Thus, it is concluded that no inventory limits are needed for ${ }^{228} \mathrm{Ra}$.

No measurements of ${ }^{107} \mathrm{Pd} \mathrm{Kd}$ values are known. However, because of its pasition on the periodic table of the elements, and its association with nickel under natural conditions, palladium is expected 


\section{HNF-SD-WM-TI-798, Rev. 0}

to behave very similarly to nickel under soil groundwater conditions. Given that nickel Kd values of $>1000 \mathrm{ml} / \mathrm{g}$ have been measured in Hanford soil and groundwater (Serne, et al, 1993), it is concluded that assigning a $\mathrm{Kd}$ of 100 to ${ }^{107} \mathrm{Pd}$ is reasonable and that no inventory limit for palladium is required.

${ }^{40} \mathrm{~K}$ is a unique isotope because it is naturally occurring, but to our knowledge, not produced in nuclear reactor processes. Thus, it can be concluded that wastes generated by nuclear processes cannot provide additional sources of ${ }^{40} \mathrm{~K}$ and that if wastes do contain ${ }^{40} \mathrm{~K}$, it is due to the presence of natural materials in the waste. Relative to natural materials that are part of waste, it is equally implausible that deliberate or inadvertent enhancement of ${ }^{40} \mathrm{~K}$ will occur. Thus, ${ }^{40} \mathrm{~K}$ inventories in waste should not exceed natural abundances. Consequently, no inventory limits are required for ${ }^{40} \mathrm{~K}$.

In conclusion, revision of inventory limits for the isotopes listed in this reference is not required. However, the $\mathrm{Kd}$ grouping shown in Table $3-5$ will be changed to show ${ }^{107} \mathrm{Pd}$ and ${ }^{226} \mathrm{Ra}$ are contained in the $\mathrm{Kd}$ of 100 group.

\section{Intruder Calculations at Longer Times}

In the present PA analysis, the waste acceptance criteria for Category 1 and Category 3 wastes were established on the basis of two intruder scenarios, the postexcavation scenario for Category 1 waste and the postdriling scenario for Category 3 waste. The time of intrusion was set at 100 years and 500 years, respectively for Category 1 and 3 limits. For most radionuclides these are the times of maximum dose for the conditions assumed in the analyses. However, ingrowth daughter products for some radionuclides have the effect of increasing potential dose at times beyond those assumed in the analyses. This condition applies primarily to the uranium decay chain radionuclides. A comparison of doses from the decay chains of each parent nuclide by ratio is provided in Table 2-1 for the post excavation scenario and in Table 2-2 for the postdrilling scenario.

If the radionuclide concentration limits provided in the present PA analysis were changed to reflect potential dose at 10,000 years postclosure, the values for each radionuclide would be decreased by the factors shown in the 10,000 year column. For example, the present Category 1 concentration limit for ${ }^{234} \mathrm{U}$ is $8.9 \times 10^{-3} \mathrm{Ci} / \mathrm{m}^{3}$. Using the 10,000 year dose, the concentration limit would be reduced to $1.9 \times 10^{-3} \mathrm{Ci} / \mathrm{m}^{3}$. 


\section{HNF-SD-WM-TI-798, Rev. 0}

Table 2-1. Ratio of the Post-Excavation Dose at 10,000 Years and Peak Time to the Initial Dose at 100 years.

\begin{tabular}{|c|c|c|c|}
\hline Radionuclide & at 10,000 Years & at Peak & Peak Year \\
\hline Th-230 & 12.3 & 12.3 & 8,900 \\
\hline U-233 & 10.9 & 15.1 & 34,000 \\
\hline$U-234$ & 4.80 & 34.3 & 190,000 \\
\hline$U-235$ & 4.75 & 20.9 & 460,000 \\
\hline$U-238$ & 1.05 & 38.4 & $3,600,000$ \\
\hline Np-237 & 1.02 & 2.16 & 550,000 \\
\hline Pu-244 & 1.21 & 1.32 & 77,000 \\
\hline
\end{tabular}

Table 2-2. Ratio of Post-Drilling Dose at 10,000 Years and Peak Time to the Initial Dose at 500 Years.

\begin{tabular}{|c|c|c|c|}
\hline Radionuclide & at 10,000 Years & at Peak & Peak Year \\
\hline Th-230 & 4.15 & 4.15 & 8,900 \\
\hline U-233 & 6.73 & 9.46 & 34,000 \\
\hline U-234 & 4.66 & 33.3 & 190,000 \\
\hline U-235 & 4.07 & 17.9 & 460,000 \\
\hline U-238 & 1.05 & 38.4 & $3,600,000$ \\
\hline Np-237 & 1.02 & 2.16 & 550,000 \\
\hline Pu-244 & 1.19 & 1.30 & 77,000 \\
\hline
\end{tabular}

It is argued that these changes to the present waste classification system are unnecessarily restrictive and that concentration limits defined at 10,000 years will be easily satisfied for all of the radionuclides for actual wastes disposed in the LLBG. The following arguments are provided: 


\section{HNF-SD-WM-TI-798, Rev. 0}

- The limits as provided are applied to each individual waste package. Given the actual waste we receive, an occasional package is disposed that approaches the limit. However, the majority of packages contain far lower concentrations of these radionuclides or do not contain them at all. Consequently, the average concentrations over the Burial Grounds for these radionuclides are orders of magnitude below the limits already listed in Table 4-24. This is shown in Table B-5 in Appendix B.

- It is possible that a waste package could contain a concentration that falls between the 10,000 year limit and the presently used limit. Without considering the average Burial Grounds concentration, that package might not be acceptable for disposal. However, given the observation that these limits are not going to be exceeded on average, disposal of packages of this type has no impact on dose calculations and should be accepted.

3. Uranium Limits.

To provide further clarification of uranium dose estimates and uranium waste acceptance criteria, a more detailed review of the uranium bearing wastes was undertaken. This review involved evaluating uranium inventories in the individual waste packages and examining Eurial Grounds records for specific waste packages that were representative of wastes provided by major uranium waste generators. A number of characteristics were revealed in this evaluation which have a direct impact on dose estimate assumptions, projected inventories, and the comparison of the activity versus mass limits le.g., 4 $\mathrm{mrem} / \mathrm{yr}$ and $20 \mu \mathrm{g} / \mathrm{l})$.

In the final PA analysis, it was shown that a major portion of the uranium bearing waste was disposed in Trench 22 of the 218-W-5 Burial Grounds in the 1989-1992 time frame. Also, all of the major generators of uranium-bearing waste are represented in the Trench 22 inventory. Consequently, a detailed summary of the uranium-bearing wastes is provided in Tables 3-1 and 3-2. Tables 3-1 and 3-2 summarize grouted and nongrouted waste characteristics, respectively.

Each table provides a breakdown of wastes based on the degree of enrichment or depletion of ${ }^{236} \mathrm{U}$. For each category of waste, the mass of waste disposed, the volume of the waste, and the specific activity of the isotopic mixture are provided. Using these parameters the total disposed activity has been calculated.

Page 4 
HNF-SD-WM-TI-798, Rev. 0

Table 3-1. Grouted Uranlum Mass and Activity In Trench 22

\begin{tabular}{|c|c|c|c|c|c|}
\hline Facility & $\begin{array}{c}\text { Mass } \\
\text { (g) }\end{array}$ & $\begin{array}{c}\text { Volume } \\
\text { (cubic meters) }\end{array}$ & $\begin{array}{l}\text { Specific Activity } \\
\text { (CVg) }\end{array}$ & $\begin{array}{l}\text { Total Activity } \\
\text { (Ci) }\end{array}$ & U-Type \\
\hline $100 \mathrm{~N}$ & 19160 & 0.21 & $8.9 E-07$ & 0.0170 & \multirow{6}{*}{ Enriched } \\
\hline $224 \mathrm{U}$ & 572 & 4.62 & 8.9E-07 & 0.0005 & \\
\hline LBLAB & 25 & 0.42 & $8.9 E-07$ & 0.0000 & \\
\hline $325(\mathrm{PNL})$ & 1803 & 0.42 & 8.9E-07 & 0.0016 & \\
\hline BATCO & 19410 & 1.89 & 7.2E-07 & 0.0140 & \\
\hline Total & 40970 & 7.56 & & 0.0330 & \\
\hline $100 \mathrm{~N}$ & 29500 & 0.21 & $6.9 E-07$ & 0.0480 & \multirow{6}{*}{ Natural } \\
\hline BNLAB & 15900 & 0.82 & $6.9 E-07$ & 0.0110 & \\
\hline ALBNY & 444 & 17.85 & $6.9 E-07$ & 0.0003 & \\
\hline AMES & 333 & 1.47 & $6.9 E-07$ & 0.0002 & \\
\hline$\angle B L A B$ & $\$ 321$ & 0.62 & 6.9E-07 & 0.0064 & \\
\hline Total & 95500 & 20.97 & & 0.0662 & \\
\hline $306 W(P N L)$ & 4446000 & 1.87 & $7.0 E-06$ & 32.1700 & \multirow{4}{*}{ Depleted } \\
\hline $325(P N L)$ & 62240 & 3.15 & 7.0E-06 & 0.4370 & \\
\hline ALQPA & 76020 & 7.95 & 7.0E-06 & 0.5300 & \\
\hline Total & 4584260 & 12.97 & & 33.1370 & \\
\hline $\begin{array}{l}\text { Grand Total } \\
\text { Average Spec }\end{array}$ & 4720730 & $\begin{array}{c}41.5 \\
(\theta)=7.0 E-06\end{array}$ & & 33.2362 & \\
\hline
\end{tabular}


HNF-SD-WM-TI-798, Rev. 0

Table 3-2. Non Grouted Uranium Mass and Activity In Trench 22

\begin{tabular}{|c|c|c|c|c|c|}
\hline Facility & $\begin{array}{c}\text { Mass } \\
\text { (g) }\end{array}$ & $\begin{array}{c}\text { Volume } \\
\text { (cubic meters) }\end{array}$ & $\begin{array}{l}\text { Specific Activity } \\
\text { (Cig) }\end{array}$ & $\begin{array}{c}\text { Total Acinity } \\
\text { (Ci) }\end{array}$ & U-Type \\
\hline BATCO & 14970 & 4.62 & $7.2 E-07$ & 0.0108 & \multirow{9}{*}{ Enriched } \\
\hline $100 \mathrm{~N}$ & 97870 & 1.26 & $8.3 E-07$ & 0.0812 & \\
\hline TWRSG & 8863 & 0.21 & 8.3E-07 & 0.0074 & \\
\hline 2240 & 422 & 0.41 & $8.3 E-07$ & 0.0004 & \\
\hline LBLAB & 72 & 1.26 & 8.3E-07 & 0.0001 & \\
\hline $209 E$ & 282 & 3.2 & 8.3E-07 & 0.0002 & \\
\hline $329(\mathrm{PNL})$ & 20 & 0.21 & $8.3 E-07$ & 0.00002 & \\
\hline $325(\mathrm{PNL})$ & 103 & 0.21 & 8.3E- 07 & 0.0001 & \\
\hline Total & 122602 & 11.38 & & 0.1001 & \\
\hline $3000(\mathrm{PNL})$ & 15370 & 1.89 & $7.0 E-06$ & 0.1076 & \multirow{9}{*}{ Depleted } \\
\hline $327 \mathrm{C}(\mathrm{PNL})$ & 1214 & 0.75 & $7.0 \mathrm{E}-06$ & 0.0085 & \\
\hline NALAB & 2531 & 12.18 & $7.0 E-06$ & 0.0597 & \\
\hline ARGON & 65515 & 2.52 & 4.0E-07 & 0.0262 & \\
\hline $324(\mathrm{PNL})$ & 37018 & 0.42 & $7.0 E-06$ & 0.2591 & \\
\hline ALOPA & 11280 & 0.81 & $7.0 \mathrm{E}-06$ & 0.0790 & \\
\hline LBLAB & 281814 & 0.84 & $3.4 E-07$ & 0.0958 & \\
\hline $327(\mathrm{PNL})$ & 443 & 1.47 & $7.0 E-06$ & 0.0031 & \\
\hline Total & 421185 & 20.88 & & 0.6390 & \\
\hline $100 \mathrm{~N}$ & 8100 & $0 \notin 2$ & $6.9 E-07$ & 0.0056 & \multirow{8}{*}{ Natural } \\
\hline CUPFC & 1409000 & 0.68 & $6.9 E-07$ & 0.9722 & \\
\hline TWRSG & 20990 & 17.21 & $6.9 E-07$ & 0.0145 & \\
\hline $327(\mathrm{PNL})$ & 490 & 0.21 & $6.9 E-07$ & 0.0003 & \\
\hline ALBNY & 1882 & 2.5 & $6.9 \mathrm{E}-07$ & 0.0013 & \\
\hline AMES & 347 & 14.64 & $6.9 E-07$ & 0.0002 & \\
\hline LBLAB & 78 & 2.31 & $6.9 E-07$ & 0.0001 & \\
\hline Total & 1440887 & 38.17 & & 0.9942 & \\
\hline $\begin{array}{l}\text { Grand Total } \\
\text { Average Spe }\end{array}$ & 1984674 & $\begin{array}{r}70.43 \\
=8.7 \mathrm{E}-07 \mathrm{Ci} / \mathrm{g}\end{array}$ & & 1.7333 & \\
\hline
\end{tabular}




\section{HNF-SD-WM-TI-798, Rev. 0}

The tables summarize the following significant characteristics of the waste:

* More than $95 \%$ of the uranium mass is contained in $<6 \%$ of the waste volume containing uranium. This is expected because the majority of uranium waste by mass is either uranium metal or uranium oxides, both of which have a high density, $\left(-19\right.$ and $7 \mathrm{~g} / \mathrm{cm}^{3}$ for metal and oxide, respectivelyl. Consequently, a small volume of uranium metal or oxide constitutes a large mass. The estimated volumes of the entire mass in Tables 3-1 and 3-2 are 0.96 and $0.35 \mathrm{~m}^{3}$ assuming an oxide or a metal form, respectively. The Burial Grounds record descriptions indicate that uranium is usually in the form of metal.

* The two dominant isotopes that contribute to the specific activities listed in Tables 3-1 and 3-2 are ${ }^{234} \mathrm{U}$ and ${ }^{238} \mathrm{U}$. ${ }^{236} \mathrm{U}$ can make up a significant portion of the total activity only if the waste is highly enriched. These wastes are at most $3 \%$ enriched, but usually about 0.9 to $1.5 \%$ enriched. The specific activities of the different wastes change as a function of the ${ }^{234} \mathrm{U}$ activity in the wastes. The degree of ${ }^{234} \mathrm{U}$ enrichment is shown by comparison with the natural uranium specific activity of $6.9 \times 10^{-7} \mathrm{Ci} / \mathrm{g}$. All enriched wastes are slightly elevated in relative ${ }^{234} \mathrm{U}$ activity. The depleted wastes can be enhanced or reduced in ${ }^{234} \mathrm{U}$ depending on the source. Note that the greatest enrichment of ${ }^{234} \mathrm{U}$ comes from the depleted uranium waste from Pacific Northwest Laboratory (PNL).

* The overail activity and average specific activity of waste disposed in Trench 22 is dominated by the PNL generated waste

In addition to the uranium inventories listed in these tables, there are many containers $(>100)$ each containing very small quantities of uranium in the range of $0.001 \mathrm{up}$ to $10 \mathrm{~g}$. It is estimated that a maximum of 500 additional grams of nongrouted uranium are present in Trench 22 .

Based on the additional uranium characteristic information determined from this review, a revised dose estimate calculation for Trench 22 waste is warranted. The following calculation is also pertinent to the discussion of the influence of isotopic variability on dose estimates and the development of waste acceptance criteria. The uranium waste is divided into three categories with each contributing to dose. These include grouted and nongrouted waste for which solubility control of radionuclide release is assumed and the dispersed uranium waste for which advection controlled release is assumed.

Page 7 


\section{HNF-SD-WM-TI-798, Rev. 0}

To estimate dose for the solubility controlled release it is necessary to determine the east-west length over which the solubility limited concentrations can be sustained. As described in the final PA analysis (Section 4.2.2.4.2), the dose from solubility controlled release is proportional to the length of the waste volume that is parallel to the general direction of groundwater flow (in this case, east-west). This distribution of the uranium bearing waste is affected by the assumption of the north-south width of the trench area and the area over which the uranium can be extended. First, although the waste is stacked over a north south width of $-13 \mathrm{~m}$, the north-south width actually covered by the trench is about $25 \mathrm{~m}$ when the unusable spaces beneath the sloping trench wall and between the adjacent trenches are considered. In this calculation, credit is taken for the flux of diluting groundwater underneath the unused space and the uranium is, in effect, considered to be distributed over the entire $25 \mathrm{~m}$. This is considered reasonable because the hypothetical downstream well could draw from the uncontaminated water as well as contaminated water, even assuming that minimal transverse dispersion occurs.

Second, the relatively small volume of uranium relative to the total capacity, coupled with the concentration of the majority of the uranium mass in a few containers restricts the area over which the solubility controlled groundwater concentrations will occur. Although the uranium waste is undoubtedly distributed over a long distance in the east west direction, the distribution of the uranium is clearly spotty as illustrated by a comparison of uranium volume with available waste volume in a trench. The total volume of uranium in the disposed waste under consideration is $\sim 1 \mathrm{~m}^{3}$ and the total volume of a trench segment that is $10 \mathrm{~m}$ long in the east-west direction is $\sim 750 \mathrm{~m}^{3}$ if the waste is assumed to be stacked $3 \mathrm{~m}$ deep. To perform the dose estimate calculation, the entire uranium inventory is assumed to be located in a band of waste that is $25 \mathrm{~m}$ wide in the north south direction.

To determine the east west length under these conditions, the area that the waste could cover must be calculated. The total mass of uranium in Tables $3-1$ and $3-2$ is about $6.7 \times 10^{8} \mathrm{~g}$. Of that mass, about $6.4 \times 10^{\circ} \mathrm{g}$ is contained in 2855 -gallon drums. If we assume the drums are about $0.57 \mathrm{~m}$ in diameter and are lined up north south, they take up a distance of about $16 \mathrm{~m}$. To calculate the distribution of the remaining uranium mass labout $3 \times 10^{5} \mathrm{~g}$ ), $9 \mathrm{~m}$ are assumed to be left in the 25 $\mathrm{m}$ wide band over which the waste can be distributed. Assuming the lower uranium oxide density of about $7 \mathrm{~g} / \mathrm{cm}^{3}$, the computed volume of the uranium is about $4.3 \times 10^{4} \mathrm{~cm}^{3}$. If that waste is distributed in a volume $1 \mathrm{~cm}$ thick, the area of distribution is $4.3 \mathrm{~m}^{2}$. With $9 \mathrm{~m}$ left in the north-south 


\section{HNF-SD-WM-TI-798, Rev. 0}

direction, the east-west length is $\sim 0.48 \mathrm{~m}$. This value is less than the $0.57 \mathrm{~m}$ width of the row of drums. Therefore, the diameter of the 55 -gallon drum $(-0.57 \mathrm{~m})$ is used in the dose calculation.

The dose estimate is calculated for the grouted and the nongrouted waste separately because of the differences in solubility limits. A dilution factor of $8.27 \times 10^{-4}$ has previously been calculated to determine the peak concentration for an infiltration rate of $0.5 \mathrm{~cm} / \mathrm{vr}$ and an east west distribution of waste over $20 \mathrm{~m}$. Increased dilution is calculated in this case because the east-west length has been reduced to $0.57 \mathrm{~m}$. The proportional dilution factor is estimated to be $2.4 \times 10^{-5}$. For the grouted waste with an assumed solubility of $1 \times 10^{-6} \mathrm{M}$ (about $2.38 \times 10^{-4} \mathrm{~g} / \mathrm{L}$ ), the peak concentration is about $5.6 \times 10^{-8} \mathrm{~g} / \mathrm{L}$. To caiculate a dose, the average specific activity for grouted waste in Table $3-1$ is used $\left(7.0 \times 10^{-8} \mathrm{Ci} / g\right)$ to calculate the peak concentration in terms of activity $\left(-3.9 \times 10^{-14} \mathrm{Ci} / \mathrm{L}\right)$. The drinking water dose is estimated by assuming an annual consumption of $730 \mathrm{~L}$ and a dose factor of $2.4 \times 10^{4} \mathrm{mrem} / \mathrm{pCi}$. The calculated dose is $0.007 \mathrm{mrem} / \mathrm{yr}$. A similar calculation for the nongrouted waste is done assuming a solubility of $2.7 \times 10^{-4} \mathrm{M}$ (about $6.4 \times 10^{-2} \mathrm{~g} / \mathrm{L}$ ) and an average specific activity of $8.9 \times 10^{-7} \mathrm{Ci} / \mathrm{g}$ (based on data in Table 3-2). The estimated dose from nongrouted waste is about $0.24 \mathrm{mrem} / \mathrm{yr}$.

Finally, dose from the $500 \mathrm{~g}$ of dispersed uranium is calculated by assuming homogenous dispersion over the $25 \mathrm{~m}$ in the north south direction. Thus, for every meter of width in the north south direction, about $20 \mathrm{~g}$ of uranium are present. Using the averaged specific activity for non grouted uranium of $8.9 \times 10^{-7} \mathrm{Ci} / \mathrm{g}$, the total activity is estimated to be about $1.8 \times 10^{-5} \mathrm{Ci}$. Recalling that the uranium limit per meter of trench width in the direction perpendicular to flow is $0.0022 \mathrm{Ci}$ for advection controlled release, and that the curie limit corresponds to a dose of $4 \mathrm{mrem} / \mathrm{yr}$, the estimated dose from the $500 \mathrm{~g}$ of dispersed uranium is $0.003 \mathrm{mrem} / \mathrm{yr}$.

The total dose from uranium waste disposed in Trench 22 from 1989 to 1992 is therefore estimated to be $0.25 \mathrm{mrem} / \mathrm{yr}$ for the drinking water scenario. This estimate is somewhat larger than that provided in the text of the PA and results from the inclusion of significant quantities of nongrouted waste in Trench 22 and the enrichment of ${ }^{234} \mathrm{U}$ in the uranium isotopic mix. The increased solubility limit for non grouted uranium is the primary contributor to the increased dose estimate. These non conservative assumptions in the previous analysis were balanced by the ultraconservative assumption in the previous analysis of a large areal spread of uranium over which solubility limited concentrations

could be sustained. Because the actual areal spread of uranium is much smaller, the estimated flux from the facility is smaller. Thus, the combination of non conservative and ultraconservative

Page 9 


\section{HNF-SD-WM-TI-798, Rev. 0}

assumptions has lead to dose estimates that are similar. In the final revision of the PA document (Section 4.4.3.2), this discussion of uranium dose estimates will replace the current discussion.

A projection of uranium waste to be disposed in the Burial Grounds is provided in Table 3-3. The estimated volumes of waste are taken from waste volume projections (Templeton and Clary, 1994) and discussions with the staff who develop the annual waste volume projections. The average $g / \mathrm{m}^{3}$ values and specific activities are taken from the current data base and Burial Grounds records. The volumes reported are total volumes, most of which will not contain uranium. To estimate projected uranium waste, it was necessary to use total volumes of disposed and projected waste from each generator (e.g., the combination of uranium free and uranium containing waste volumes) because the projected volumes of uranium containing waste are not available. From these data, projected mass and activities of uranium have been calculated.

The estimated mass of uranium is less than twice that disposed in the 1989 to 1992 time frame. This reflects the abnormally large source provided by PNL (primarily from $306 \mathrm{~W}$ ) in this time period. Because this particular source of waste is essentially gone, a much smaller mass of uranium waste to be disposed is projected. It is interesting to note that the average specific activity is somewhat higher than natural uranium and is consistent with the Trench 22 average specific activity which did not include $306 \mathrm{~W}$ waste. It is expected that the slightly elevated average specific activity is a reasonable value because elevated ratios of ${ }^{234} \mathrm{U}$ are present in both enriched and depleted uranium sources. This expectation is also supported by the projected combinations of uranium wastes. Both enriched and depleted uranium are larger contributors than natural uranium in waste streams projected for future disposal.

Given the relatively small projected mass of additional uranium to be disposed in the entire 200 West LLBG and the expectation that large fractions of the additional waste will continue to be disposed in a small number of waste packages, the dose projection used above for Trench 22 should be applicable to the total inventory calculation. The dose estimate of $0.25 \mathrm{mrem} / \mathrm{yr}$ is proposed for the total Burial Grounds and should be a conservatively large estimate because of the limited area over which the uranium can be distributed le.g., the total additional uranium mass is less than $2 \mathrm{~m}^{3}$ if the density of uranium oxide is assumed) and the length of the total Burial Grounds capacity available for disposal (about $1700 \mathrm{~m}$ ). 
Table 3-3. 30 Yoar Projected Uranlum Inventory Data

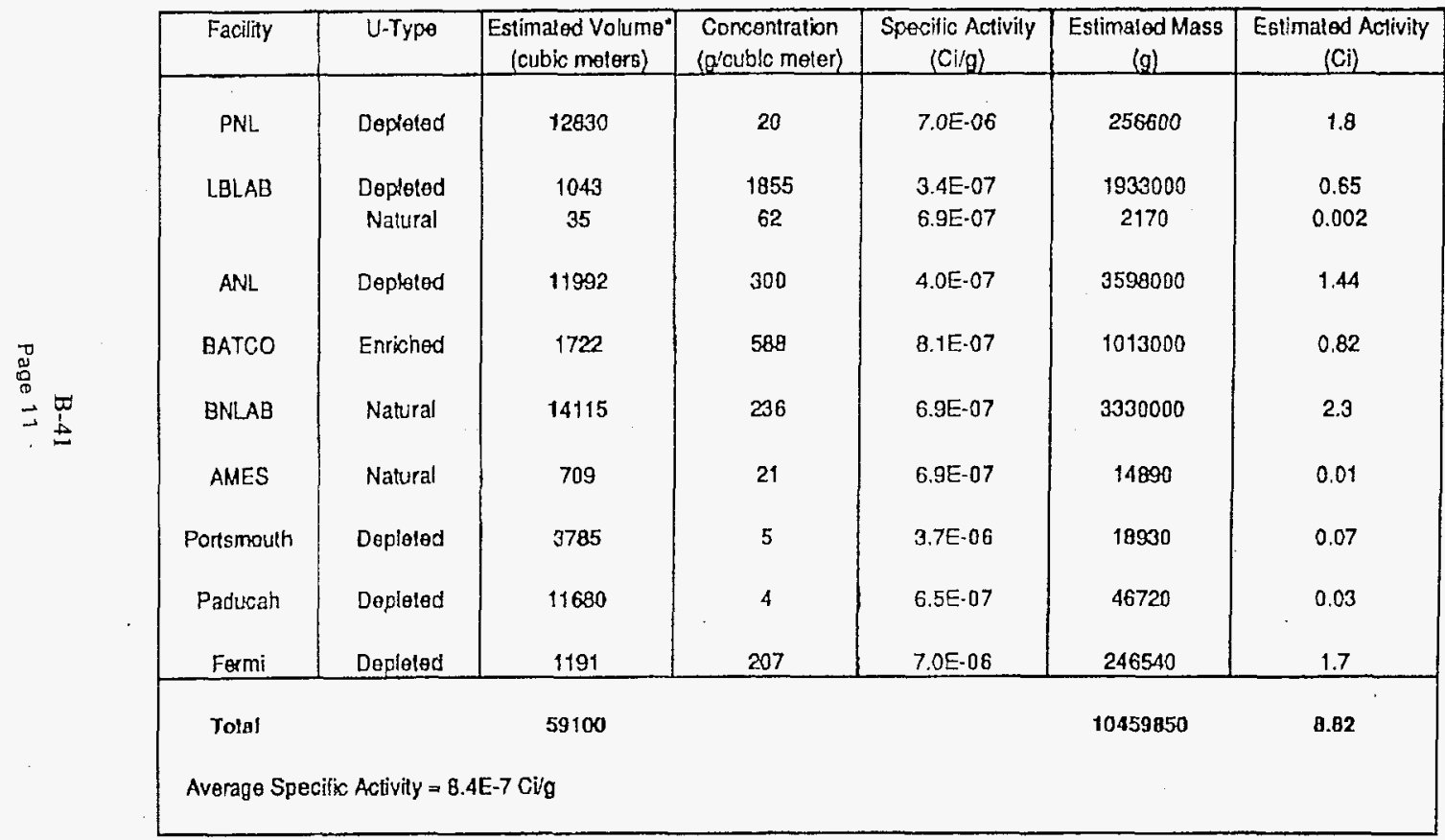

- The volumes listed in this table are tolal projected volumes from each generator, not just uranium containing waste volumes as shc in Tables 3-1 and 3-2. 


\section{HNF-SD-WM-TI-798, Rev. 0}

Finally, the results of this analysis can be used to consider the questions of waste acceptance criteria and mass versus activity performance objectives. The evaluation of uranium wastes shows that uranium mass tends to be highly concentrated in a few waste packages and highly diluted in many waste packages. In the highly concentrated packages, solubility limits will be sustained, but in the highly diluted packages, solubility limits will not be reached because of dilution. Thus, it is reasonable to maintain both the advection controlled and solubility controlled limits provided in the present analysis (Section 4.4.2.1). In addition, the analysis presented above indicates that the requirement to grout wastes containing uranium inventories that exceed the advection controlled inventory limits is more than adequate to satisfy the performance objectives.

With regard to the comparison of the $4 \mathrm{mrem} / \mathrm{yr}$ and the $20 \mu \mathrm{g} / \mathrm{L}$ limit, the average projected specific activity of future disposed uranium $\left(8.4 \times 10^{-7} \mathrm{Ci} / \mathrm{g}\right)$ is used to make the conversion and compare the two limits. In making this assumption, the groundwater plume activity is assumed to maintain the isotopic ratio present in the facility. Assuming the stated specific activity, $20 \mu g / L$ corresponds to $16.8 \mathrm{pCi} / \mathrm{L}$. This compares with the $22.8 \mathrm{pCi} / \mathrm{L}$ that corresponds to a groundwater drinking limit of $4 \mathrm{mrem} / \mathrm{yr}$. It could be argued that the activity limits defined in the present PA analysis should be reduced by the ratio of 16.8 to 22.8 . However, given the uncertainties of these calculations, the actual average waste specific activity, and the conservatisms that have been introduced into these calculations, this difference is considered to be insignificant. If the activity limits are predicted to be satisfied, then the mass limits will also be satisfied. Given the characteristics of uranium waste and the quantity of uranium waste expected to be disposed, this is a reasonable expectation.

\section{Reference}

Templeton, K.J. and J.L. Clary, 1994, "1994 Solid Waste Forecast Container Volume Summary," WHC-EP-0803, Westinghouse Hanford Company, Richland, Washington.

\section{Confidence in Model Results}

A wide variety of soil sample and water analysis data are available which provide indications of radionuclide transport in the soil column. In most cases, the data are insufficient to do a model calibration exercise. The one exception is the 241-T-106 Tank leak. A summary of the modeling exercise is provided below. Despite the scarcity of complete data sets, there is sufficient information to verify qualitatively the relative mobility of various radionuclides in the soil column and to confirm 


\section{HNF-SD-WM-TI-798, Rev. 0}

that the general assumptions of retardation as expressed by sorption coefficients are adequate to evaluate the likelihood of groundwater contamination by radionuclides present in the solid waste inventory.

A number of radionuclides are identified in the present PA analysis that are expected to be very mobile in the Hanford Site hydrogeologic system. These radionuclides have been assigned a $K d$ value of $O$ $\mathrm{mL} / \mathrm{g}$ to indicate that these radionuclides should be transported with fluxing water with essentially no retardation. The primary radionuclides in this category that are present in solid waste streams include tritium, iodine, technetium, and uranium. In fact, all of these radionuclides are currently present in contaminant plumes in the unconfined aquifer. These plumes have been generated from extensive discharge of contaminated fluids into cribs, ponds and ditches at much higher rates than normal groundwater recharge from precipitation events. It is important to note that other radionuclides known to be present in the liquid waste are not observed in the unconfined aquifer. These include strontium, cesium, americium, plutonium and radium. These radionuclides are expected to be moderately to highly sorbing and should not have reached the unconfined aquifer during the liquid waste disposal period. Unfortunately, the distributions of these radionuclides in the soil column are not known for these waste sites. This information may become available as a result of remediation activities. As discussed below, some relative transport characteristics for cesium and strontium are available at other sites.

One qualitative indication of plutonium transport in the soil column is available from the excavation of soil underneath the 216-Z-9 crib (Ludowise, 1978; Reisenauer, 1959). The crib is located just to the east of the 200 West Area LLBG. Approximately $4 \times 10^{5} \mathrm{~L}$ of plutonium contaminated liquids were disposed over a seven year period (1955 -1962) into the crib. Remote sensing equipment showed that the plutonium was highly concentrated in the upper soil layers of the crib and led to a concern that a criticality event might occur. During excavation in 1978 , the top $30 \mathrm{~cm}$ of soil were removed and $58 \mathrm{~kg}$ of plutonium were recovered. No firm evaluation of the remaining plutonium in the soil column was provided, although the remote sensing data suggested that the $30 \mathrm{~cm}$ contained about $60 \%$ of the plutonium. These data suggest that relatively little movement of plutonium occurred in the soil column .

A number of modeling studies has been conducted at the Hanford Site that provide limited justification for $K_{d}$ values used in the PA. These studies are summarized below.

Page 13 


\section{HNF-SD-WM-TI-798, Rev. 0}

241-T-106 Tank Leak Study.

The 241-T-106 single-shell tank is located in the 200 West Area, just east of the LLBG. The $\operatorname{tank}$ 241-T-106 leak was first documented in 1973 (ARHCO 1973). A report by the U.S. Atomic Energy Commission (AEC 1973) provided a detailed chronology of the leakage that began on or about April 20, 1973. Leakage stopped on June 10,1973, when the pumpable liquid contents of the tank were removed (Routson et al. 1979). The total duration of the leak was approximately 52 days, during which $115,000 \mathrm{gal}$ of supernate were lost from the tank.

Most of the radionuclide inventory of the supernate solution within the tank consisted of ${ }^{114} \mathrm{Ce}$ and ${ }^{144} \mathrm{Pr},{ }^{137} \mathrm{Cs},{ }^{87} \mathrm{Sr},{ }^{80} \mathrm{Sr},{ }^{106} \mathrm{Ru}$ and ${ }^{100} \mathrm{Rh}$, with lesser amounts of the other radionuclides (Routson et al. 1979). With the exception of ${ }^{106} \mathrm{Ru}$ and ${ }^{106} \mathrm{Rh}$, the inventory is characterized by long half-lives and high sorption coefficients. The inventory corresponds to $2.67 \times 10^{5}$ total $\mathrm{Ci}$ of ${ }^{106} \mathrm{Ru}$ and $3.85 \times 10^{4}$ total $\mathrm{Ci}$ of ${ }^{137} \mathrm{Cs}$ that leaked from the tank. The ${ }^{108} \mathrm{Ru}$ has a half-life of $1 \mathrm{yr}$ and sorption coefficients are generally considered to be approximately zero; the ${ }^{137} \mathrm{Cs}$ has a half-life of $30.17 \mathrm{yr}$ (Walker et al. 1984 and is considered to be highly sorbed by Hanford Site soils. The movement of ${ }^{106} \mathrm{Ru}$ is of interest because its transport should be essentially concurrent with the fluid front.

The leakage apparently occurred on the southeast side of the tank because the contaminant plume is centered around this area. Figure 1 shows a plan view and a vertical cross-sectional view of the plume as measured in the summer of 1973, after the leak had been detected and the tank pumped out. The concentrations shown in the figure were measured on a per-liter-volume-of-soil basis. The contaminant transport is shown for ${ }^{106} \mathrm{Ru},{ }^{144} \mathrm{Ce}$, and ${ }^{137} \mathrm{Cs}$. The ${ }^{106} \mathrm{Ru}$ is the most mobile of the three radionuclides and traveled the farthest; the ${ }^{137} \mathrm{Cs}$ is the least mobile and was contained within a small zone around the base of the tank. The configuration of the ${ }^{106} \mathrm{Ru}$ plume appears to be approximately circular, with a radius of about 15 to $20 \mathrm{~m}$ in plan view and a maximum depth of about $20 \mathrm{~m}$.

Figure 2 shows the measured ${ }^{106} \mathrm{Ru} 1-\mu \mathrm{Ci} / \mathrm{L}$ isopleths for 1973 versus 1978 ; the ${ }^{106} \mathrm{Ru} 1-\mu \mathrm{Ci} / \mathrm{L}$ isopleth appears to have migrated about 5 to $7 \mathrm{~m}$ downward at dry wells 107 and 108 , but shows little movement elsewhere. Because of its relatively short (1-yr) half-life, ${ }^{106} \mathrm{Ru}$ would decay from the estimated $2.7 \times 10^{11} \mu \mathrm{Ci}$ leaked from the tank in 1973 to about $8.4 \times 10^{\circ} \mu \mathrm{Ci}$ in 1978 . However, the decay process alone is not sufficient to explain the relative stability of the $1 \mu \mathrm{Ci} / \mathrm{L}$ isopleth of the ${ }^{106} \mathrm{Ru}$ observed in 1978.

Page 14 
HNF-SD-WM-TI-798, Rev. 0

Two modeling studies have been reported for T-106 tank leak (Smoot et al., 1989): a one-dimensional simulation of the infiltration of the meteoric water into surface sediments; and a three-dimensional simulation of contaminant plume migration in the vadose zone underneath Tanks 241-T-106. The results of both one- and three-dimensional simulations are summarized below.

Infiltration through the upper $2 \mathrm{~m}$ of soil cover was simulated for the period of 1947 to 2020 using hydraulic properties estimated for the backfill sediments. The one-dimensional infiltration simulations indicate that approximately 77 percent $(13.1 \mathrm{~cm} / \mathrm{yr})$ of annual precipitation infiltrates below a depth of $2 \mathrm{~m}$. The three-dimensional simulation results suggest that the increased flushing of the soil column, resulting from higher infiltration, may increase the potential rate of movement of the ${ }^{106}$ Ru plume. The simulated ${ }^{106} \mathrm{Ru}$ plume approached, but did not enter the water table by the early 1980 's; after that time, the simulated ${ }^{108}$ Ru plume began to recede because of radioactive decay (Fig. 3). The simulated plume for ${ }^{108} \mathrm{Ru}$ appears to be consistent with field data. The simulated ${ }^{137} \mathrm{Cs}$ plume is highly sorbed by minerals in the sediments beneath the tank and migrates much less than ${ }^{106} \mathrm{Ru}$; the

${ }^{137} \mathrm{Cs}$ plume becomes essentially stationary after about 50 days (Fig. 4 ). This result is similar to that observed in the field; the ${ }^{137} \mathrm{Cs}$ sorption appears to be sufficiently high that even the increased infiltration does not significantly increase the mobility of the ${ }^{137} \mathrm{Cs}$ plume. For these modeling studies, a Kd value of $0.5 \mathrm{~mL} / \mathrm{g}$ was used for ${ }^{108} \mathrm{Ru}$ and $100 \mathrm{~mL} / \mathrm{g}$ for ${ }^{137} \mathrm{Cs}$.

\section{0-BP-1 Onerable Unit.}

A modeling study using PORFLO-3 was summarized in the report "Phase 1 Remedial Investigation Report for 200-BP-1 Operable Unit" (DOE, 1993, Section 5). Using $K_{d}$ values presented in Table 4-1, soil concentrations predicted by the model compared favorably to those measured in crib soils and the subsurface infiltration gravel/soil zone (Table 5-11, DOE, 1993). Although the model is not calibrated in an exact sense due to large uncertainties in the recharge estimates and simplifications used, it did provide a fairly reasonable comparison of model calculation with the field measurements. 
HNF-SD-WM-TI-798, Rev. 0

Table 4-1.

Summary of Kd Data Specific to Hanford under Ambient Conditions

\begin{tabular}{|c|c|c|c|}
\hline Species & $\begin{array}{c}\text { Probable Kd } \\
(\mathrm{mL} / \mathrm{g})\end{array}$ & $\begin{array}{c}\text { Range in Kd } \\
(\mathrm{mL} / \mathrm{g})\end{array}$ & Quality of Data \\
\hline \hline${ }^{3} \mathrm{H}(\mathrm{HTO})$ & 0 & 0 & 1 \\
\hline Cs-137 & 500 & $500-10,000$ & 2 \\
\hline Sr-90 & 20 & $5-100$ & 2 \\
\hline Total U & 1 & $0-3$ & 3 \\
\hline Pu-238,239/240 & 100 & $100-2,000$ & 3 \\
\hline Tc-99 & 0 & $0-1$ & 2 \\
\hline
\end{tabular}

Quality Rating

(1) Kd values are very well known, little chance for variation because of chemical changes.

(2) Kd values are well known, variability caused by competing salts, $\mathrm{pH}$. Fh and organics generally understood.

(3) Kd values are fairly well known, variability caused by chemical factors (competing salts, redox, organics, etc.) not well documented.

\section{N-Springs Studies.}

Two modeling studies were performed to predict ${ }^{80} \mathrm{Sr}$ transport 30 year into the future. In the first study, Lu (1991) used the two-dimensional code VAM $20 H$ to simulate the migration of ${ }^{90} \mathrm{Sr}$ from liquid waste disposal facilities in the 100-N Area to the Columbia River. A baseline calibration analysis was made using published concentrations of ${ }^{80} \mathrm{Sr}$ at $\mathrm{N}$-Springs on the south bank of the columbia River adjacent to the 100-N Area. Since the measured concentration of ${ }^{\circ 0} \mathrm{Sr}$ at $\mathrm{N}$ Springs is only a small fraction of the concentration discharged to the disposal facility, Lu (1991) speculated that retardation mechanisms other than sorption were present. Lu suggested that the sludge layer at the bottom of the disposal facility consisting of calcium carbonate, iron oxide, and clay acted as a filter for particulate ${ }^{80} \mathrm{Sr}$. Under this conceptual model, an excellent agreement was achieved between the published and simulated concentrations for the year 1973 through 1990 using $\mathrm{Kd}$ value of $10 \mathrm{~mL} / \mathrm{g}$ in both Hanford formation and Ringold Formation sediments. 
The results from the two-dimensional modeling were used to help define a three-dimensional model subsequently simulated by the PORFLO-3 code (Connelly et. al., 1991). A modeling process similar to that used for two-dimensional conceptual model was used for PORFLO-3 simulations. Connelly et al. used $\mathrm{Kd}$ values of $30 \mathrm{~mL} / \mathrm{g}$ for Hanford formation and $24.5 \mathrm{~mL} / \mathrm{g}$ for Ringold Formation. The PORFLO-3 simulation estimated an arrival time of ${ }^{\circ 0} \mathrm{Sr}$ that was $4 \mathrm{yr}$ less than that observed and, hence, overpredicted the concentration of ${ }^{\circ 0} \mathrm{Sr}$ at $\mathrm{N}$ Spring. Again, although the model was not calibrated, it did approximate the groundwater flow and contaminant transport in the 100-N Area based on field observations. Different $K d$ values utilized in these two studies may be attributed to varying geometries $(2 D$ vs $3 D)$ used in the simulations.

\section{Summary}

The various field data and calibration studies discussed above represent the best available information at the site. Qualitative examples of mass transport of highly mobile, moderately mobile and relatively immobile radionuclides that are common to solid wastes have been provided. Calibration studies have also been provided that fit the sorption data assumed in the PA analysis fairly well. In addition, the low-level glass performance assessment program has plans to conduct model verification for contaminant transport at the Injection Test site which has been described in Appendix $G$ of the current PA document.

Based on this information, it is concluded that the mass transport assumptions in the PA analysis, primarily the $\mathrm{Kd}$ assumptions, are adequately supported by the field and modeling data. Several arguments suggest that additional field experiments and associated modeling are unnecessary to improve confidence in the mass transport assumptions. First, the modeling results are actually fairy insensitive to the selection of $K d$ values le.g., transport times of tens of thousands of years are predicted for normal infiltration conditions of $0.5 \mathrm{~cm} /$ year and moderate $\mathrm{Kd}$ values of $10 \mathrm{ml} / \mathrm{g}$ or morel. Second, the only real concern is the confidence in the travel times to the unconfined aquifer for moderately and highly sorbing radionuclides because we have assumed no retardation for poorly sorbing radionuclides. The modeling data provide some confidence that estimates of mass transport for a moderately sorbing radionuclide $\left({ }^{80} \mathrm{Sr}\right)$ and a highly sorbing radionuclide $\left({ }^{137} \mathrm{C} s\right)$ are consistent with the use of the retardation concept. Third, the cost of conducting tracer experiments and associated modeling is high. For highly sorbing radionuclides, the likelihood af observing transport under realistic infiltration conditions is nil. 


\section{HNF-SD-WM-TI-798, Rev. 0}

\section{References}

AEC, 1973, "Report on the Investigation of the 106-T Tank Leak at the Hanford Reservation, Richland, Washington. TID 26431, U.S.A.E.C., Richland, Washington.

ARHCO, 1973. "Tank 241-T-106 Leak Investigation", ARH-2874, Atlantic Richfield Hanford Company., Richland, Washington.

Cantrell, K. J and R. J. Serne, 1992. "Literature Search For 200-BP-1 sorption," a letter report for WHC from PNL, Pacific Northwest Laboratory, Richland, Washington.

Connelly, M. P., J. D. Davis, and P. D. Rittmann, 1991. "Numerical Simulation of ${ }^{\circ 0} \mathrm{Sr}$ transport from the 100-N Area Liquid Waste Disposal Facilities," WHC-SD-TA-001.

DOE, 1993. "Phase 1 Remedial Investigation Report for 200-BP-1 Operable Unit," DOE/RL-92-70, REV.O Volume 1, United States Department of Energy, Richland, WA.

Lu, A. H., 1991. "Simulations of Strontium-90 Transport from the 100-N Area to the Columbia River Using VAM2DH," WHC-EP-0369.

Ludowise, 1978, "Report on Plutonium Mining Activities at 216-Z-9 Enclosed Trench." RHO-ST-21, Rockwell Hanford Operations, Richland, Washington.

Reisenauer, E.A., 1959, "216-Z-9 Core Sampling Data," HW-61787 RD, General Electric Company, Richland, Washington.

Routson, R.C., W.H. Price, D.J. Brown, and K.R. Fecht, 1979, "High-Level Waste Leakage from the 241-T-106 Tank at Hanford, RHO-ST-14, FHO, Richland, Washington.

Smoot, J.L., J.E. Szecsody, B. Sagar, G.W. Gee, and C.T. Kincaid, 1989, "Simulations of Infiltration of Meteoric WAster and Contaminant Plume Movement in the Vadose Zone at Single Shell Tank 241 T-106 at the Hanford Site, WHC-El-0332, Westinghouse Hanford Company, Richland, Washington. 


\section{HNF-SD-WM-TI-798, Rev. 0}
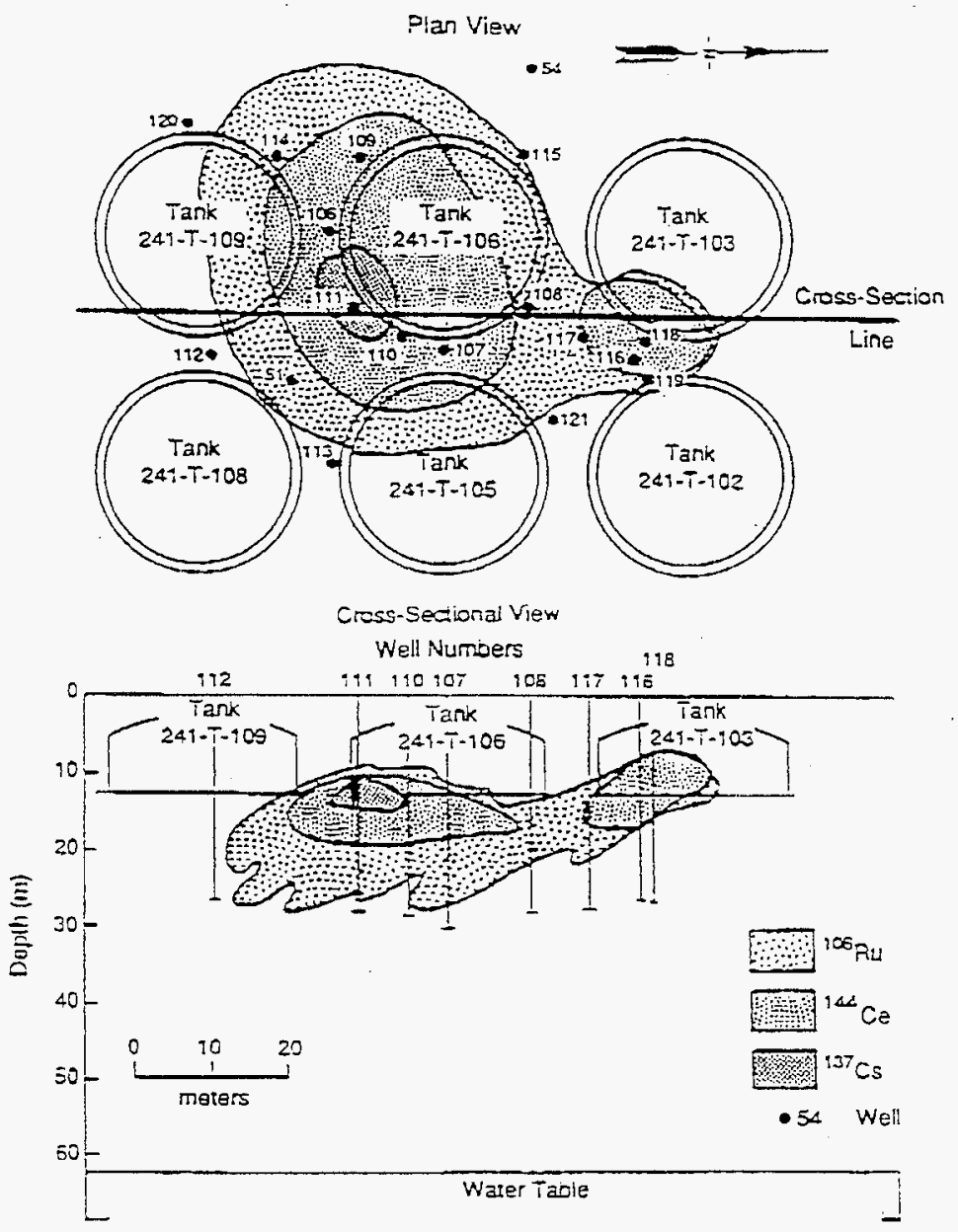

P590-020

Figure 1. Plan and Vertical Cross-Sectional Views of the $1973137 \mathrm{CS}$, it $\mathrm{Ce}$, and $106 \mathrm{Ru}$ (I $\mu \mathrm{Cj} / \mathrm{L}$ ) Volumetric Isopleths (after Routson et al., 1979). 

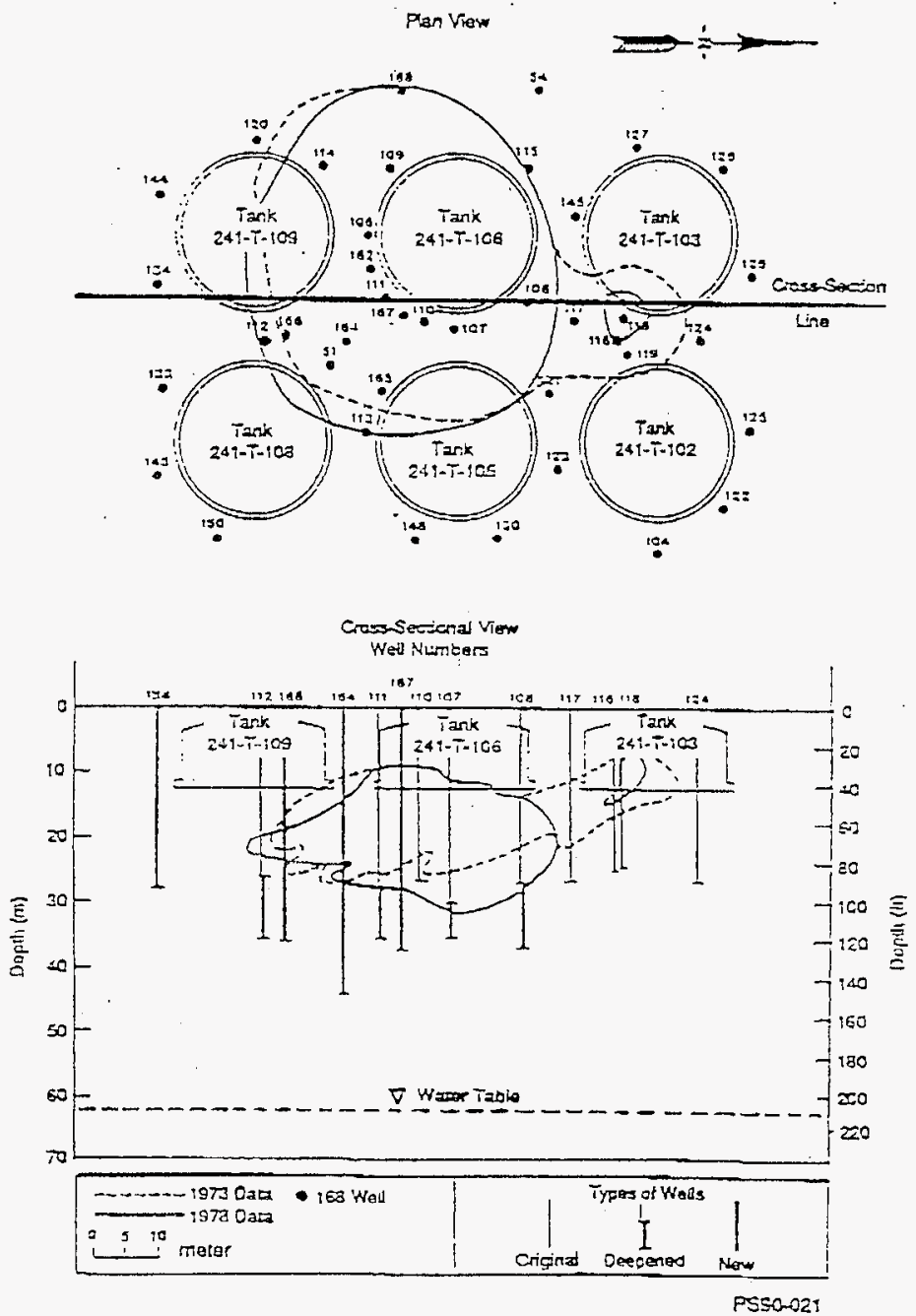

Figure 2. Plan and Vertical Cross-Sectionai Views of the 1973 and 1978 $106 \mathrm{Ru}(1 \mathrm{kC} / \mathrm{L})$ Volumetrtc Isopleths

(after Routson et a1., I979). 
HNF-SD-WM-TI-798, Rev. 0

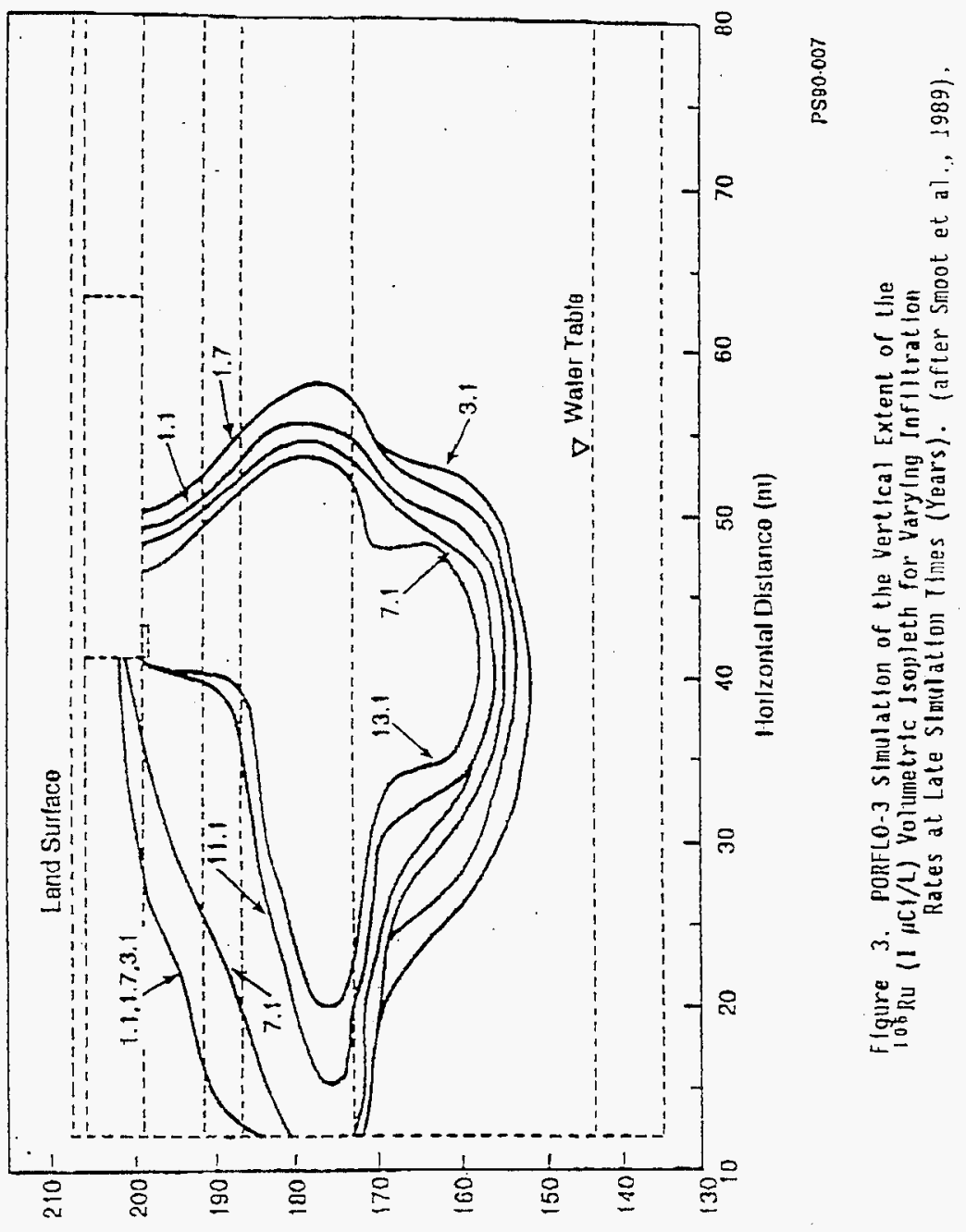

(w) Uop̣ena! 


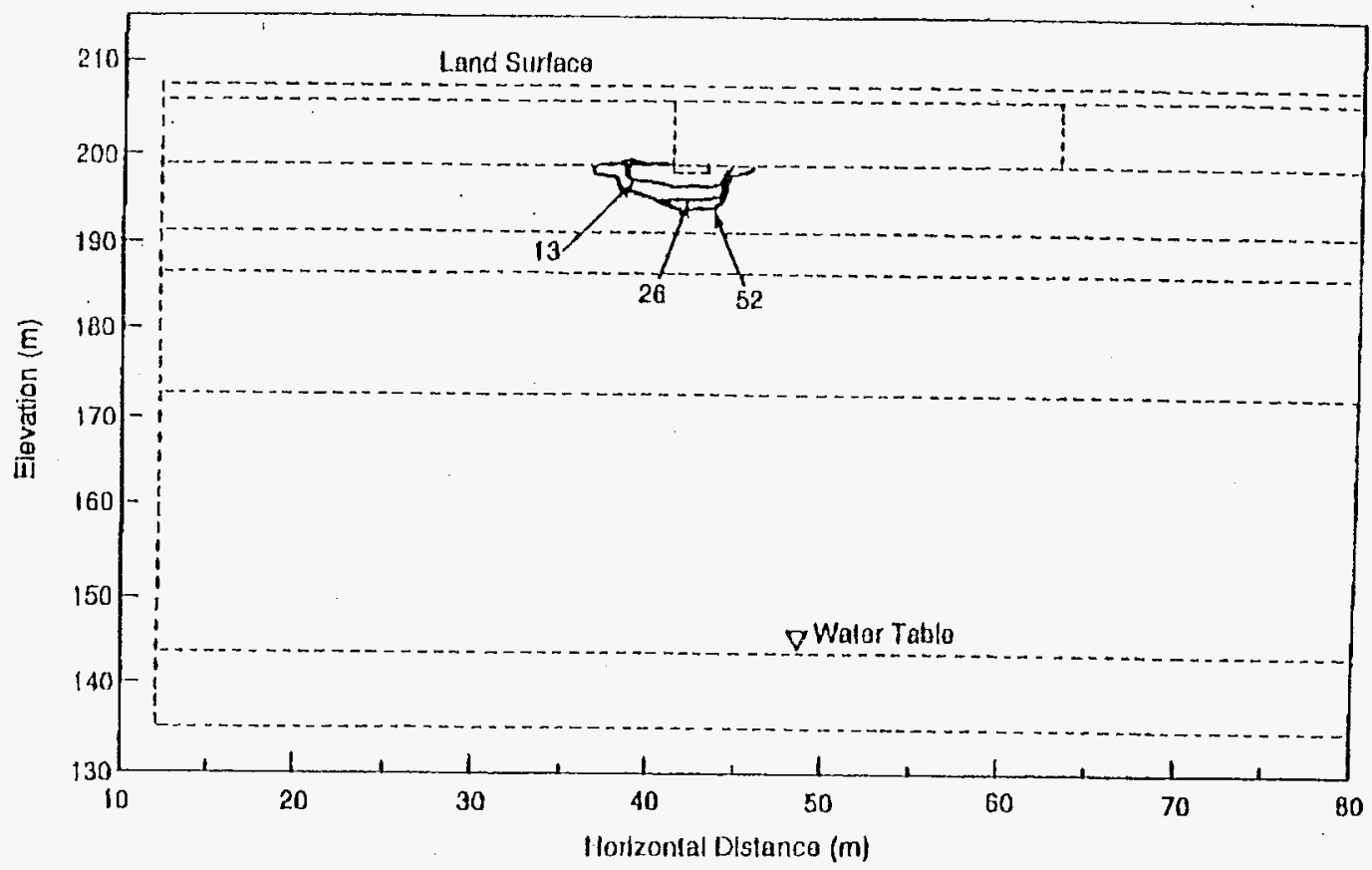

Flgure 4. POAflo-3 Simulation of the Vertical Extent of the [3C Cs (I $\mu \mathrm{Cl} / \mathrm{L})$ Volumetric Isoploth for

Varying Infiltration Rates (Days). (after Smoot et al., 1989). 
DISTRIBUTION SHEET

\begin{tabular}{|c|c|c|c|c|c|}
\hline \multirow{2}{*}{$\begin{array}{l}\text { To } \\
\text { Distribution }\end{array}$} & \multirow{2}{*}{\multicolumn{3}{|c|}{$\begin{array}{l}\text { From } \\
\text { M.I. Wood }\end{array}$}} & \multicolumn{2}{|l|}{ Page 1 of 1} \\
\hline & & & & \multicolumn{2}{|c|}{ Date $12 / 20 / 96$} \\
\hline \multicolumn{4}{|l|}{ Project Title/Work Order } & \multicolumn{2}{|c|}{ EDT No. 620426} \\
\hline \multicolumn{4}{|c|}{$\begin{array}{l}\text { Addendum to the Performance Assessment Analysis for Low-Level } \\
\text { Waste Disposal in the } 200 \text { West Area Active Burial Grounds }\end{array}$} & \multicolumn{2}{|l|}{ ECN No. $\quad N / A$} \\
\hline Name & MSIN & $\begin{array}{c}\text { Text } \\
\text { With All } \\
\text { Attach. }\end{array}$ & Text Only & $\begin{array}{c}\text { Attach./ } \\
\text { Appendix } \\
\text { Only }\end{array}$ & $\begin{array}{l}\text { EDT/ECN } \\
\text { Only }\end{array}$ \\
\hline $\begin{array}{l}\text { N.R. Brown } \\
\text { A.K. Crowe } 11 \\
\text { R.D. Hildebrand } \\
\text { R. Khalee1 } \\
\text { C.T. Kincaid } \\
\text { P.J. Macbeth } \\
\text { F.M. Mann } \\
\text { P.D. Rittman } \\
\text { M.I. Wood }\end{array}$ & $\begin{array}{l}\text { K6-51 } \\
\text { S7-55 } \\
\text { H0-12 } \\
\text { H0-31 } \\
\text { K9-33 } \\
\text { R3-82 } \\
\text { H0-31 } \\
\text { H0-31 } \\
\text { H6-06 }\end{array}$ & $\begin{array}{l}1 \\
2 \\
1 \\
1 \\
1 \\
1 \\
1 \\
1 \\
2\end{array}$ & & & \\
\hline
\end{tabular}

Central Files

A3-88 Origina] 